\title{
Intermediate-Valence Tautomerism in
}

\section{Decamethylytterbocene Complexes of}

\section{Methyl-Substituted Bipyridines}

Corwin H. Booth, ${ }^{*, \dagger}$ Daniel Kazhdan, ${ }^{\dagger,}$ Evan L. Werkema, ${ }^{\dagger, \ddagger}$ Marc D. Walter,,,+ Wayne W. Lukens, ${ }^{\dagger}$ Eric D. Bauer, ${ }^{\text {Il }}$ Yung-Jin Hu, ${ }^{\S}$, Laurent Maron,,$\|, \perp$ Odile Eisenstein, ${ }^{\perp}$ Martin Head-Gordon, ${ }^{\dagger,}$ and Richard A. Andersen ${ }^{\dagger, \ddagger}$

Chemical Sciences Division, Lawrence Berkeley National Laboratory, Berkeley, California 94720, USA, Department of Chemistry, University of California, Berkeley, California 94720, USA, Materials Physics and Applications Division, Los Alamos National Laboratory, Los Alamos, New Mexico 87545, USA, Nuclear Sciences Division, Lawrence Berkeley National Laboratory, Berkeley, California 94720, USA, Université de Toulouse, INSA-UPS-LPCNO and CNRS-LPCNO, 135 avenue de Rangueil, F-31077 Toulouse, France, and Institut Charles Gerhardt, Université Montpellier 2, CNRS UMR 5253, CC 1501, place E. Bataillon, 34095 Montpellier, France

E-mail: chbooth@lbl.gov

\footnotetext{
${ }^{*}$ To whom correspondence should be addressed

${ }^{\dagger}$ Chemical Sciences Division, Lawrence Berkeley National Laboratory, Berkeley, California 94720, USA

${ }^{\ddagger}$ Department of Chemistry, University of California, Berkeley, California 94720, USA

${ }^{\mathbb{I}}$ Materials Physics and Applications Division, Los Alamos National Laboratory, Los Alamos, New Mexico 87545, USA

${ }^{\S}$ Nuclear Sciences Division, Lawrence Berkeley National Laboratory, Berkeley, California 94720, USA

"Université de Toulouse, INSA-UPS-LPCNO and CNRS-LPCNO, 135 avenue de Rangueil, F-31077 Toulouse, France

${ }^{\perp}$ Institut Charles Gerhardt, Université Montpellier 2, CNRS UMR 5253, CC 1501, place E. Bataillon, 34095 Montpellier, France
} 
Draft: Wednesday $26^{\text {th }}$ January, 2011, 11:54

\begin{abstract}
Multiconfigurational, intermediate valent ground states are established in several methylsubstituted bipyridine complexes of bispentamethylcyclopentadienylytterbium, $\mathrm{Cp}_{2}^{*} \mathrm{Yb}\left(\mathrm{Me}_{x^{-}}\right.$ bipy). In contrast to $\mathrm{Cp}_{2}^{*} \mathrm{Yb}$ (bipy) and other substituted-bipy complexes, the nature of both the ground state and the first excited state are altered by changing the position of the methyl or dimethyl substitutions on the bipyridine rings. In particular, certain substitutions result in multiconfigurational, intermediate valent open-shell singlet states in both the ground state and the first excited state. These conclusions are reached after consideration of single-crystal $\mathrm{x}$-ray diffraction $(\mathrm{XRD})$, the temperature dependence of $\mathrm{x}$-ray absorption near-edge structure (XANES), extended x-ray absorption fine-structure (EXAFS), and magnetic susceptibility data, and are supported by CASSCF-MP2 calculations. These results place the various $\mathrm{Cp}_{2}^{*} \mathrm{Yb}$ (bipy) complexes in a new tautomeric class, that is, intermediate-valence tautomers.
\end{abstract}

\title{
1 Introduction
}

Recent experimental and theoretical studies of certain $\mathrm{Ce}$ - and Yb-based organometallic complexes ${ }^{1-15}$ have highlighted the importance of multiconfigurational interactions in understanding their electronic, structural, and magnetic properties. The canonical examples include $\mathrm{Ce}(\mathrm{cot})_{2}$, also known as "cerocene," where cot $=$ cyclooctatetraene $=\mathrm{C}_{8} \mathrm{H}_{8}$, and $\mathrm{Cp}_{2}^{*} \mathrm{Yb}($ bipy $)$, where $\mathrm{Cp}^{*}=$ pentamethylcyclopentadienyl, and bipy $=2,2^{\prime}$-bipyridine. In these materials, various Configuration Interaction $(\mathrm{CI})$ calculations ${ }^{1-3,12-15}$ indicate that a singlet ground state develops that is lower in energy than that of the triplet state because it is a mixture of various open- and closed-shell singlet configurations. These singlet states are therefore multiconfigurational, that is, quantum mechanical admixtures of configurations with different $\mathrm{f}$ occupations, and are intermediate valent, abbreviated below as IV, in the sense that the effective valence for each $\mathrm{Ce}$ or $\mathrm{Yb}$ atom is non-integral. In the molecules cited above, the singlet ground state is mostly composed of the open-shell singlet configuration, although covalence between the ligand and the closed-shell configuration may play 
a role, at least in cerocene. ${ }^{14}$ The observed temperature-independent paramagnetism (TIP) at low temperature is then due to a van Vleck interaction between the ground-state singlet and the triplet configuration at some higher energy. The lanthanide valence, as expected, does not change significantly with temperature. The most dramatic confirmation of this model, however, is the measured IV state from $L_{\mathrm{III}}$-edge x-ray absorption near-edge structure (XANES) spectroscopy.

As the literature on this subject grows, it is clear that the degree of interaction between various singlet states can be varied, sometimes in a systematic fashion, ${ }^{12}$ creating a nearly continuous range of intermediate valence and magnetic behavior. Within this picture, therefore, it should be possible to selectively stabilize different state configurations, for instance, creating a triplet ground state with an IV excited singlet state, or creating an IV singlet ground state with a different IV excited singlet state.

In this article, we report experimental and theoretical results on a series of methyl-substituted bipy complexes of $\mathrm{Cp}_{2}^{*} \mathrm{Yb}$ that can be described by the latter scenario, that is, by two distinct openshell singlet, IV states separated by only hundredths of an $\mathrm{eV}$, generating an equilibrium between two IV singlet states. This behavior is akin to that found in the traditional view of valence tautomers, such as in the cobalt semiquinones, ${ }^{16}$ in that the valence changes with temperature, except that the states are two IV states, rather than two integral-valent states. In fact, the role of intermediate valence is similar to that proposed by LaBute et al. ${ }^{17}$ for the cobalt semiquinones, whereby the molecule transitions from a low-spin, integral valent state at low temperatures to a high-spin, IV state at high temperatures. The unusual situation described below for the methyl-substituted bipyridine derivative of $\mathrm{Cp}_{2}^{*} \mathrm{Yb}$ is an IV ground and first excited state that is achieved through the Me substitution onto the bipy ligand, in stark contrast to what occurs with other substitutions, such as $\mathrm{CO}_{2}$ Me. ${ }^{12}$ These conclusions are supported by magnetic and XANES studies of both monoand di-methyl-substituted $\mathrm{Cp}_{2}^{*} \mathrm{Yb}$ (bipy) compounds, in which the position of the substitution on the bipy radical anion is varied. Complete Active Space Self-Consistent Field (CASSCF) calculations are reported on the mono-methyl-substituted compounds, including at the second-order perturbation theory (CASSCF-MP2) level. These calculations are improved over the previous cal- 
culations ${ }^{12}$ by using a larger active space and $\left(\mathrm{C}_{5} \mathrm{Me}_{5}\right)_{2} \mathrm{Yb}$ instead of $\left(\mathrm{C}_{5} \mathrm{H}_{5}\right)_{2} \mathrm{Yb}$ and are in good agreement with the experimental data.

\section{Experimental Section}

\subsection{Synthesis}

The substituted bipyridine adducts of $\mathrm{Cp}_{2}^{*} \mathrm{Yb}$ discussed in this article are listed in Table 1 along with some of their physical properties. The numbering of the carbon positions on the bipyridine rings are shown in Scheme 1. The complexes are prepared and characterized as outlined in earlier $\operatorname{articles}^{18-21}$ and these details are available as Supporting Information.

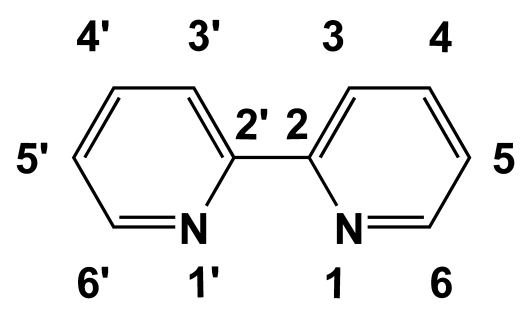

Scheme 1: Numbered positions on the bipyridine rings.

\subsection{Magnetic measurements}

${ }^{1} \mathrm{H}$ NMR spectra were taken on Bruker AVQ-400 and AV-300 spectrometers. All chemical shifts are reported in $\delta$ units. Variable-temperature spectra in the form of $\delta$ vs. $\mathrm{T}^{-1}$ plots are available as Supporting Information. Magnetic susceptibility measurements were made for all samples at 5 kOe and 40 kOe in a 7 T Quantum Design Magnetic Properties Measurement System, which utilizes a superconducting quantum interference device (SQUID). Sample containment and other experimental details have been described previously. ${ }^{12}$ The $\chi$ vs. $T$ data are shown in Figure 2. Note that the low-temperature upturn is not reproducible from sample-to-sample, and so is not intrinsic. The amount of this impurity contribution is less than $2 \%$ of the $\mathrm{Yb}$ atoms (see Section 5). 
Table 1: Some Physical Properties of $\mathrm{Cp}_{2}^{*} \mathrm{Yb}\left(\right.$ bipy $\left.^{\prime}\right)$ Adducts ${ }^{a}$

\begin{tabular}{|c|c|c|c|c|c|c|c|}
\hline \multirow[b]{2}{*}{ Compound } & \multirow{2}{*}{$\begin{array}{l}\mu_{\mathrm{eff}}\left(\mu_{B}\right) \\
(300 \mathrm{~K})\end{array}$} & $\lambda_{\max }(\mathrm{nm})^{b}$ & \multicolumn{5}{|c|}{${ }^{1} \mathrm{H}$ NMR chemical shifts ${ }^{c}$} \\
\hline & & $\varepsilon\left(\times 10^{-3}, \mathrm{~L} \mathrm{~mol}^{-1} \mathrm{~cm}^{-1}\right)$ & $6,6^{\prime}$ & $5,5^{\prime}$ & $4,4^{\prime}$ & $3,3^{\prime}$ & $\mathrm{Cp}^{*}$ \\
\hline \multirow[t]{2}{*}{$\mathrm{Cp}_{2}^{*} \mathrm{Yb}(4-\mathrm{Me}-\mathrm{bipy})$} & 2.27 & 786 & 154.5 & 11.1 & 30.5 & -13.3 & 3.9 \\
\hline & & 3.1 & 150.6 & 6.0 & $-9.3(\mathrm{Me})$ & -8.6 & \\
\hline \multirow[t]{2}{*}{$\mathrm{Cp}_{2}^{*} \mathrm{Yb}(5-\mathrm{Me}-\mathrm{bipy})$} & 1.17 & 778 & 134.4 & 18.3 & 37.6 & -9.1 & 3.6 \\
\hline & & 4.0 & 130.0 & $-9.1(\mathrm{Me})$ & 34.3 & -8.3 & \\
\hline \multirow{2}{*}{$\mathrm{Cp}_{2}^{*} \mathrm{Yb}(6-\mathrm{Me}-\mathrm{bipy})$} & 0.79 & 785 & 112.3 & 16.2 & 29.3 & -4.3 & 2.1 \\
\hline & & 3.3 & $97.6(\mathrm{Me})$ & 12.7 & 27.8 & -5.2 & \\
\hline $\mathrm{Cp}_{2}^{*} \mathrm{Yb}\left(4,4^{\prime}-\mathrm{Me}_{2}\right.$-bipy $)$ & $1.18^{d}$ & & 144.1 & 8.2 & $-9.3(\mathrm{Me})$ & -9.5 & 3.8 \\
\hline \multirow{2}{*}{$\mathrm{Cp}_{2}^{*} \mathrm{Yb}\left(5,5^{\prime}-\mathrm{Me}_{2}\right.$-bipy $)$} & 1.13 & 783 & 102.7 & $-14.5(\mathrm{Me})$ & 38.2 & -5.8 & 3.2 \\
\hline & & 1.6 & & & & & \\
\hline \multirow{4}{*}{$\mathrm{Cp}_{2}^{*} \mathrm{Yb}\left(6,6^{\prime}-\mathrm{Me}_{2}\right.$-bipy $)$} & 0.53 & 929 & $6.9(\mathrm{Me})$ & $7.92, \mathrm{~d}^{e}$ & $9.66, \mathrm{t}$ & $6.47, \mathrm{~d}^{e}$ & 1.9 \\
\hline & & 1.0 & & $J=8 \mathrm{~Hz}$ & $J=8 \mathrm{~Hz}$ & $J=8 \mathrm{~Hz}$ & \\
\hline & & 811 & & & & & \\
\hline & & 1.7 & & & & & \\
\hline
\end{tabular}

${ }^{a}$ The numbering of the positions in the bipyridine ring is shown in Scheme $1 .{ }^{b}$ Only the longest wave length absorption, $\lambda_{\max }$ is given in cyclohexane, other values are in Supporting Information, $\varepsilon$ is the molar absorptivity. ${ }^{c}{ }^{1} \mathrm{H}$ NMR chemical shifts in ppm relative to $\mathrm{Me}_{4} \mathrm{Si}$, in $\mathrm{C}_{6} \mathrm{D}_{6}$ at $20^{\circ} \mathrm{C}$, variable temperature spectra, as $\delta$ vs. $T^{-1}$ plots are available as Supporting Information. ${ }^{d}$ The value for this sample is slightly higher than that from a previously reported ${ }^{19}$ sample. ${ }^{e}$ These assignments may be interchanged. 


\subsection{X-ray absorption}

The samples were prepared for $\mathrm{x}$-ray absorption experiments as described previously. ${ }^{12}$ In particular, the same methods were used to protect these air-sensitive compounds from oxygen and water contamination. X-ray absorption measurements were made at the Stanford Synchrotron Radiation Lightsource on beamlines 10-2 and 11-2. The samples were prepared and loaded into a liquid helium-flow cryostat at the beamline as described previously. ${ }^{12}$ Data were collected at temperatures ranging from $20 \mathrm{~K}$ to $300 \mathrm{~K}$, using a $\mathrm{Si}(220)$ double crystal monochromator, except for data collected on $\mathrm{Cp}_{2}^{*} \mathrm{Yb}\left(4,4^{\prime}-\mathrm{Me}_{2}\right.$-bipy), which used a $\mathrm{Si}(111)$ double-crystal monochromator. Generally, harmonic rejection was accomplished by detuning the crystals to $50 \%$ beam reduction, although occasionally a rejection mirror was employed. Preliminary data using a focused beam on a sample of $\mathrm{Cp}_{2}^{*} \mathrm{Yb}\left(4,4^{\prime}-\mathrm{Me}_{2}\right.$-bipy) indicated strong radiation damage over the course of several minutes. Subsequent measurements were performed using a defocused or unfocused beam, and a new part of the sample was measured for each temperature if any damage was suspected. The energy resolution was determined using a standard copper foil, and was always much less $(\sim 0.7-1.0$ $\mathrm{eV}$ ) than the core-hole lifetime of the $\mathrm{Yb} L_{\mathrm{III}}$ edge of approximately $4.2 \mathrm{eV} .^{22} \mathrm{~A} \mathrm{Yb}_{2} \mathrm{O}_{3}$ reference sample was measured simultaneously, and all spectra were energy calibrated by setting the energy at the first inflection point in the $\mathrm{Yb}_{2} \mathrm{O}_{3} \mathrm{Yb} L_{\mathrm{III}}$ absorption edge to $8943 \mathrm{eV}$.

XANES data were reduced by subtracting a line extrapolated from the pre-edge region and normalizing the absorption about $50 \mathrm{eV}$ beyond the edge threshold energy.

Due to a variety of factors (much more time consuming scans, radiation damage concerns, large number of samples, etc.) fewer extended x-ray absorption fine-structure (EXAFS) data were collected for these samples than XANES data. EXAFS data are available at low temperature, between $20 \mathrm{~K}$ and $30 \mathrm{~K}$, for all samples, at $300 \mathrm{~K}$ for $\mathrm{Cp}_{2}^{*} \mathrm{Yb}\left(4-\mathrm{Me}\right.$-bipy), $\mathrm{Cp}_{2}^{*} \mathrm{Yb}\left(4,4^{\prime}\right.$ $\mathrm{Me}_{2}$-bipy) and $\mathrm{Cp}_{2}^{*} \mathrm{Yb}\left(5,5^{\prime}-\mathrm{Me}_{2}\right.$-bipy $)$, and at $150 \mathrm{~K}$ and $225 \mathrm{~K}$ for $\mathrm{Cp}_{2}^{*} \mathrm{Yb}\left(5,5^{\prime}-\mathrm{Me}_{2}\right.$-bipy). Data reduction and fitting utilize the RSXAP $\operatorname{codes}^{23}$ and use standard procedures. ${ }^{24}$ In particular, pre-edge background subtractions follow a Victoreen formula to estimate absorption from other processes, $\mu_{\text {pre }}$, and the absorption from the $\mathrm{Yb} L_{\mathrm{III}}$ edge, $\mu_{\mathrm{a}}(E)$ is isolated from the total ab- 
sorption $\mu(E)$, by taking $\mu_{\mathrm{a}}(E)=\mu(E)-\mu_{\mathrm{pre}}(E)$. The post-edge, or embedded atom, absorption $\mu_{0}(E)$, is estimated with a 7-knot cubic spline. The photoelectron wavenumber, $k$, is determined using the energy at the half-height of the absorption edge as the threshold energy, $E_{0}$, using $k=\sqrt{\left(2 m_{e} / \hbar^{2}\right)\left(E-E_{0}\right)}$, where $E$ is the incident photon energy. The EXAFS oscillations are then calculated as $\chi(k)=\mu_{\mathrm{a}}(k) / \mu_{0}(k)-1$.

The data were fit using theoretical backscattering functions calculated by the FEFF7 code $^{25}$ from a cluster based on the $228 \mathrm{~K}$ crystal structure of $\mathrm{Cp}_{2}^{*} \mathrm{Yb}\left(4,4^{\prime}-\mathrm{Me}_{2}\right.$-bipy). ${ }^{19} \mathrm{All} \mathrm{Yb}-\mathrm{C}$ and Yb-N single scattering paths are included up to the $\mathrm{Yb}-\mathrm{C}\left(5,5^{\prime}\right)$ near $4.7 \AA$. All $\mathrm{Yb}-\mathrm{H}$ and multiple scattering paths, denoted $\mathrm{Yb}-\mathrm{H} / \mathrm{MS}$, with up to 4 legs are included in a single scattering path for the fits. These paths are used for all compounds reported here. The number of neighbors, $N$, for each fitted path is held fixed to the nominal crystal structure, which is the same for all the compounds within the fit range. The exception is the $\mathrm{Yb}-\mathrm{H} / \mathrm{MS}$ path, the amplitude of which is less meaningful and is therefore allowed to float in the fits. A single $\Delta E_{0}$ shift is used for each compound. The amplitude reduction factor $S_{0}^{2}$ was found to be $0.90 \pm 0.05$ by fitting all the low-temperature data. This value was then fixed in all the fits reported here. Any distortions or potential phase impurities, etc., are therefore reflected in the mean-squared displacement (Debye-Waller) factors, $\sigma^{2}$. The data are fit in $r$-space, and all Fourier transforms (FTs) are to $k^{2}$-weighted data and are taken between $2.5 \AA$ and $15.0 \AA^{-1}$, using a Gaussian window with a $0.3 \AA^{-1}$ width. All fits are to data between 2.0 and $4.5 \AA$ and therefore have about 22 independent data points ${ }^{26}$ which are fit using 14 fit parameters, corresponding to about 8 degrees of freedom. Error bars are obtained using a Monte-Carlo method. ${ }^{27}$

\subsection{Computational details}

The ytterbium center was treated with a small-core relativistic pseudopotential (RECP) ([Ar] + $3 \mathrm{~d})^{28}$ in combination with its adapted basis set (segmented basis set that includes up to $\mathrm{g}$ functions).

The carbon, nitrogen, oxygen, and hydrogen atoms were treated with an all-electron double- $\zeta$, 6-31G(d,p), basis set. ${ }^{29}$ All the calculations were carried out with the Gaussian 03 suite of pro- 
grams ${ }^{30}$ either at the Density Functional Theory (DFT) level using the B3PW91 $1^{31,32}$ hybrid functional or at the CASSCF level. The geometry optimizations were performed without any symmetry constraints at either the DFT or the CASSCF level.

Calculations have been performed using several methods, including DFT, CASSCF with various active spaces, and CASSCF-MP2. Since we have found that so-called "intruder-state problems" 33 occur in calculations on the dimethyl complexes, the calculations described in this article focus on the 4-,5- or 6-methylbipyridine adducts of $\mathrm{Cp}_{2}^{*} \mathrm{Yb}$. Geometry optimization were carried out at the DFT level. Previous studies have shown that the DFT geometry is in excellent agreement with those obtained at the CASSCF level, ${ }^{12}$ although the optimized ground state is a triplet, $\mathrm{f}^{13, \uparrow}\left(\pi^{*}\right)^{1, \uparrow}$. This favoring of the triplet in such a DFT calculation is expected, since the self-interaction correction to the exchange-correlation energy is large for localized states, as in f-orbitals.

\section{Results: Experimental}

\subsection{Characterization}

The solid-state crystal structure of $\mathrm{Cp}_{2}^{*} \mathrm{Yb}\left(6,6^{\prime}-\mathrm{Me}_{2}\right.$-bipy) is displayed in Figure 1. Selected bond distances for $\mathrm{Cp}_{2}^{*} \mathrm{Yb}\left(5,5^{\prime}-\mathrm{Me}_{2}\right.$-bipy), $\mathrm{Cp}_{2}^{*} \mathrm{Yb}(6-\mathrm{Me}-$ bipy $)$, and $\mathrm{Cp}_{2}^{*} \mathrm{Yb}\left(6,6^{\prime}-\mathrm{Me}_{2}\right.$-bipy) are listed in Table 2. Note that the crystal structure of $\mathrm{Cp}_{2}^{*} \mathrm{Yb}(6-\mathrm{Me}-\mathrm{bipy})$ is disordered. The crystal structures of each of these compounds, available as Supporting Information, are similar; however, three individual structures of $\mathrm{Cp}_{2}^{*} \mathrm{Yb}\left(6,6^{\prime}-\mathrm{Me}_{2}\right.$-bipy) are known, since when the complex is crystallized from methylcyclohexane, it crystallizes in the space group Pbca with two unique molecules in the unit cell. When benzene is the crystallization solvent, the complex crystallizes in space group $P 2_{1} / c$ with one molecule in the unit cell, as shown in Figure 1. The ORTEP of both molecules are available as Supporting Information. Table 2 also summarizes the important bond lengths for other $\mathrm{Cp}_{2}^{*} \mathrm{Yb}\left(\mathrm{bipy}^{\prime}\right)$ compounds. The geometries of all the complexes are derived from the union of a bent sandwich $\mathrm{Cp}_{2}^{*} \mathrm{Yb}$ fragment and a bipyridine ligand with idealized $C_{2 v}$ symmetry. Table 2 


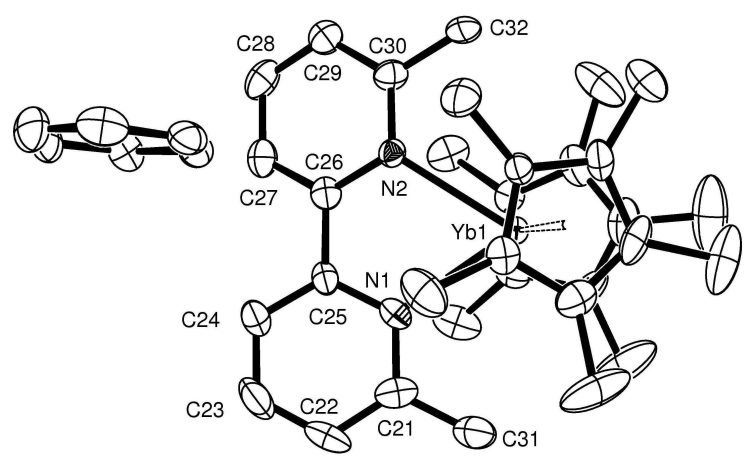

Figure 1: Crystal structure of $\mathrm{Cp}_{2}^{*} \mathrm{Yb}\left(6,6^{\prime}-\mathrm{Me}_{2}\right.$-bipy) when crystallized from benzene. Note that the $\mathrm{C} 25$ and $\mathrm{C} 26$ sites are at the 2 and $2^{\prime}$ positions on the bipyridine rings (Scheme 1). All other structures for complexes reported here are similar, apart from the presence of the benzene molecule of crystallization. Further details regarding the crystal structures are available as Supporting Information.

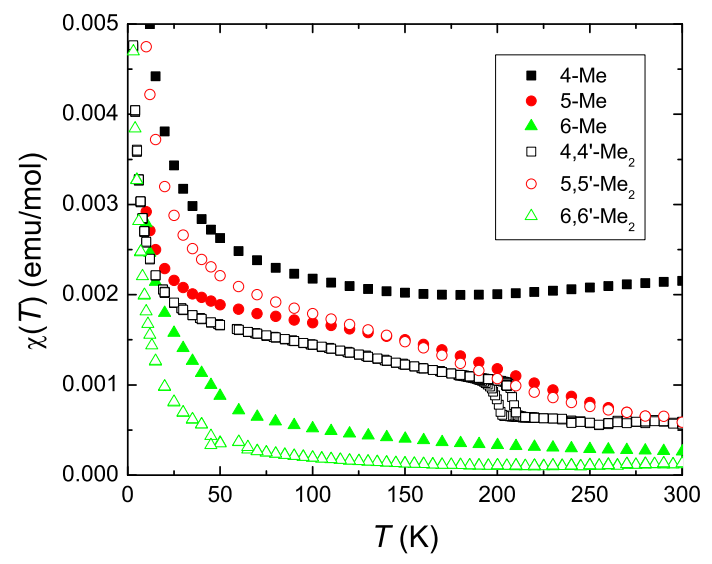

Figure 2: Magnetic susceptibility, $\chi(T)$, for all Me-substituted samples as a function of temperature in a field of $5 \mathrm{kOe}$.

orders the molecules with decreasing average $\mathrm{Yb}-\mathrm{C}\left(\mathrm{Cp}^{*}\right)$ distances, an order that closely parallels the averaged $\mathrm{Yb}-\mathrm{N}$ distances. The averaged $\mathrm{Yb}-\mathrm{C}$ distances range from $2.74 \AA$ to $2.59 \AA$ in $\mathrm{Cp}_{2}^{*} \mathrm{Yb}(\mathrm{py})_{2}$ and $\left[\mathrm{Cp}_{2}^{*} \mathrm{Yb}(\text { bipy })\right]^{+}$as the valence of ytterbium changes from two to three, respectively. The averaged $\mathrm{Yb}-\mathrm{C}$ distances in the complexes lie between these extreme values, as does the ytterbium valence, an observation that is amplified and quantitatively developed below.

Figure 2 shows the magnetic susceptibility data collected at 5 kOe. As shown in Table 1, the effective magnetic moments of the complexes at $300 \mathrm{~K}$ are smaller than expected, a property shared with the other bipy complexes described previously. ${ }^{18-21}$ In addition, the $\mu_{\text {eff }}$ strongly depends on 
Table 2: Selected Bond lengths and Angles in $\mathrm{Cp}_{2}^{*} \mathrm{Yb}\left(\mathrm{bipy}^{\prime}\right)$ Adducts from XRD

\begin{tabular}{|c|c|c|c|c|c|}
\hline Compound & $\begin{array}{c}\mathrm{Yb}-\mathrm{C}\left(\mathrm{Cp}^{*}\right)^{a} \\
\text { avg., } \AA\end{array}$ & $\begin{array}{l}\text { Yb- } \mathrm{N}^{a} \\
\text { avg., } \AA\end{array}$ & $\begin{array}{c}\mathrm{C}(2)-\mathrm{C}\left(2^{\prime}\right)^{b} \\
\AA\end{array}$ & $\begin{array}{l}\text { Temp } \\
{ }^{\circ} \mathrm{C}\end{array}$ & Ref. \\
\hline $\mathrm{Cp}_{2}^{*} \mathrm{Yb}(\mathrm{py})_{2}$ & $2.74 \pm 0.04$ & $2.565 \pm 0.005$ & & 25 & 34 \\
\hline \multicolumn{6}{|l|}{$\begin{array}{r}\mathrm{Cp}_{2}^{*} \mathrm{Yb}\left(6,6^{\prime}-\mathrm{Me}_{2} \text {-bipy) }\right. \\
{\text { (methylcyclohexane })^{c}}^{C}\end{array}$} \\
\hline molecule 1 & $2.74 \pm 0.02$ & $2.492 \pm 0.004$ & $1.450(10)$ & -105 & this work \\
\hline molecule 2 & $2.74 \pm 0.03$ & $2.516 \pm 0.002$ & $1.446(10)$ & -105 & this work \\
\hline$(\text { benzene })^{d}$ & $2.74 \pm 0.01$ & $2.510 \pm 0.001$ & $1.487(9)$ & -119 & this work \\
\hline $\mathrm{Cp}_{2}^{*} \mathrm{Yb}(6-\mathrm{Me}-\mathrm{bipy})^{e}$ & $2.69 \pm 0.03$ & $2.46 \pm 0.01$ & $1.43(2)$ & -148 & this work \\
\hline $\mathrm{Cp}_{2}^{*} \mathrm{Yb}\left(4,4^{\prime}-\mathrm{Me}_{2}\right.$-bipy $)$ & $2.67 \pm 0.02$ & $2.396 \pm 0.002$ & $1.464(4)$ & -45 & 19 \\
\hline $\mathrm{Cp}_{2}^{*} \mathrm{Yb}\left(5,5^{\prime}-\mathrm{Me}_{2}\right.$-bipy $)$ & $2.65 \pm 0.01$ & $2.339 \pm 0.004$ & $1.454(4)$ & -117 & this work \\
\hline \multicolumn{6}{|l|}{$\mathrm{Cp}_{2}^{*} \mathrm{Yb}(\text { bipy })^{f}$} \\
\hline molecule 1 & $2.63 \pm 0.01$ & $2.321 \pm 0.003$ & $1.436(9)$ & 25 & 18 \\
\hline molecule 2 & $2.61 \pm 0.01$ & $2.317 \pm 0.007$ & $1.433(9)$ & 25 & 18 \\
\hline$\left[\mathrm{Cp}_{2}^{*} \mathrm{Yb}(\text { bipy })\right]^{+g}$ & $2.59 \pm 0.01$ & $2.372 \pm 0.005$ & $1.492(4)$ & -100 & 18 \\
\hline
\end{tabular}

${ }^{a}$ The value after \pm is the average deviation from the mean. ${ }^{b}$ The value in parentheses is the standard deviation. ${ }^{c}$ The space group, when crystallized from methylcyclohexane, is Pbca and the molecule contains two independent molecules in the unit cell, molecules 1 and 2.

${ }^{d}$ The space group, when crystallized from benzene, is $P 2_{1} / c$ and the unit cell contains a benzene molecule of crystallization. ${ }^{e}$ The Me-bipy ligand is disordered, see Supporting Information for details. ${ }^{f}$ The space group is $P b c a$ and the unit cell contains two independent molecules, molecules 1 and 2. ${ }^{g}$ The anion is $\left[\mathrm{Cp}_{2}^{*} \mathrm{YbCl}_{2}\right]^{-}$. 
the number and position of the methyl group(s) on the bipy rings, as do the $\chi T$ vs. $T$ plots (see below). Table 1 shows that the visible spectra have intense absorptions around $800 \mathrm{~nm}$, which are associated with the $\pi-\pi^{*}$ transition in the bipyridine radical anion. ${ }^{35}$

In an earlier article, ${ }^{19}$ the ${ }^{1} \mathrm{H}$ NMR chemical shifts of $\mathrm{Cp}_{2}^{*} \mathrm{Yb}\left(4,4^{\prime}-\mathrm{Me}_{2}\right.$-bipy) at $20^{\circ} \mathrm{C}$ for the bipyridine resonances were shown to lie in four discrete regions, referred to as A, B, C, and D, and assigned to $\mathrm{H}(6), \mathrm{H}(3), \mathrm{H}(5)$, and $\mathrm{H}(4)$, respectively; see footnote $a$ in Table 1. A plot of the isotropic shifts of the A resonances, assigned to $\mathrm{H}(6)$ at $293 \mathrm{~K}$, vs. $\chi T$ (300 K) is linear, resulting in the important inference that the magnetic behavior is a molecular property of the individual molecules, not an average property of all the molecules in the solid. The assignment of the A resonance was based on the notion that the most strongly deshielded resonances are those closest to the paramagnetic center, that is, those at $\mathrm{H}(6)$. This assignment is confirmed by the ${ }^{1} \mathrm{H} \mathrm{NMR}$ spectra chemical shifts of (6,6'-Me ${ }_{2}$-bipy) and 6-Me-bipy reported in Table 1. It is noteworthy that the $\mathrm{Cp}_{2}^{*} \mathrm{Yb}(6-\mathrm{Me}$-bipy) complex has eight resonances, two of which are strongly deshielded at $\delta 112.3$ and 97.6 in an area ratio of $1: 3$, due to $\mathrm{H}(6)$ and $\mathrm{Me}(6)$, respectively. In addition, the variable temperature spectra show that their slopes in the $\delta$ vs. $T^{-1}$ plot (available as Supporting Information) are nearly parallel, which shows that the chemical shifts are determined by the dipolar or pseudocontact contribution as previously outlined. ${ }^{19,36}$ In contrast, the chemical shifts of the $\left(6,6^{\prime}-\mathrm{Me}_{2}\right.$-bipy) derivative show a different pattern as the $\mathrm{Me}(6)$ resonance at $\delta 6.9$ is about 90 ppm upfield from the $\mathrm{Me}(6)$ resonance in $\mathrm{Cp}_{2}^{*} \mathrm{Yb}(6-\mathrm{Me}-\mathrm{bipy})$. The other chemical shifts are not strongly perturbed from those in the free ligand, their coupling is resolved, and the chemical shifts are essentially independent of temperature (available as Supporting Information), implying that $\mathrm{Cp}_{2}^{*} \mathrm{Yb}\left(6,6^{\prime}-\mathrm{Me}_{2}\right.$-bipy) is only weakly paramagnetic, a deduction consistent with the low value of $\mu_{\mathrm{eff}}=0.53 \mu_{B}$ at $300 \mathrm{~K}$.

In contrast to the chemical shift pattern of $\mathrm{H}(6)$ and $\mathrm{Me}(6)$, the $\mathrm{H}(5), \mathrm{Me}(5)$ and $\mathrm{H}(4), \mathrm{Me}(4)$ resonances have opposite signs, as do their slopes in the $\delta$ vs. $T^{-1}$ plots (available as Supporting Information). This behavior shows that the chemical shifts at these positions in the bipy rings are largely determined by the contact contribution to the chemical shift as outlined previously. ${ }^{19,36}$ 
However, the chemical shifts in region B and C were assigned to the $\mathrm{H}(3)$ and $\mathrm{H}(5)$ sites, respectively. ${ }^{19}$ Since $\mathrm{Cp}_{2}^{*} \mathrm{Yb}(5-\mathrm{Me}-\mathrm{bipy})$ and $\mathrm{Cp}_{2}^{*} \mathrm{Yb}\left(5,5^{\prime}-\mathrm{Me}_{2}\right.$-bipy) are now known and their chemical shifts uniquely determined, these previously advocated assignments must be reversed. ${ }^{19}$ The new assignments in Table 1 are internally consistent and follow the trend $\delta_{6}>\delta_{3}>\delta_{5}>\delta_{4}$.

\subsection{X-ray absorption}

XANES data are displayed in Figure 3 and Figure 4. The magnitude of the peak near $8938 \mathrm{eV}$ is a measure of the relative involvement of $\mathrm{Yb}$ (II), while the peak near $8946 \mathrm{eV}$ is indicative of $\mathrm{Yb}$ (III). Isosbestic points provide strong evidence that changes with temperature involve only two different valence states. Fits to these data include an integrated pseudo-Voigt as a model of the edge step (essentially an arctan function), together with a pseudo-Voigt to model each resonance peak. An example of such a fit is shown in Figure 5. An additional negative pseudo-Voigt peak is included to roughly model the first EXAFS oscillation, at about $8956 \mathrm{eV}$ in the example.

From these fits, the average valence for each sample is determined as a function of temperature by taking the area of each peak $A_{i}$ and estimating the number of f-holes from

$$
n_{\mathrm{f}}=\frac{A_{\mathrm{Yb}(\mathrm{III})}}{A_{\mathrm{Yb}(\mathrm{II})}+A_{\mathrm{Yb}(\mathrm{III})}} .
$$

This procedure has been shown to be accurate by comparing similar fits to those that utilize valence

standards, such as using $\mathrm{LuAl}_{3}$ data to fit data from the intermediate valence compound $\mathrm{YbAl}_{3} \cdot{ }^{37}$ The results of such fits are shown in Figure 6, and repeated for the data from $\mathrm{Cp}_{2}^{*} \mathrm{Yb}\left(4,4^{\prime}-\mathrm{Me}_{2}\right.$-bipy) in Figure 7. Note that the previously determined structural and hysteretic magnetic transition ${ }^{19}$ is accompanied by an abrupt, hysteretic valence transition.

Examples of EXAFS data and fit quality are in Figure 8, and fit results are summarized in Table 3, Table 4, and Table 5. 


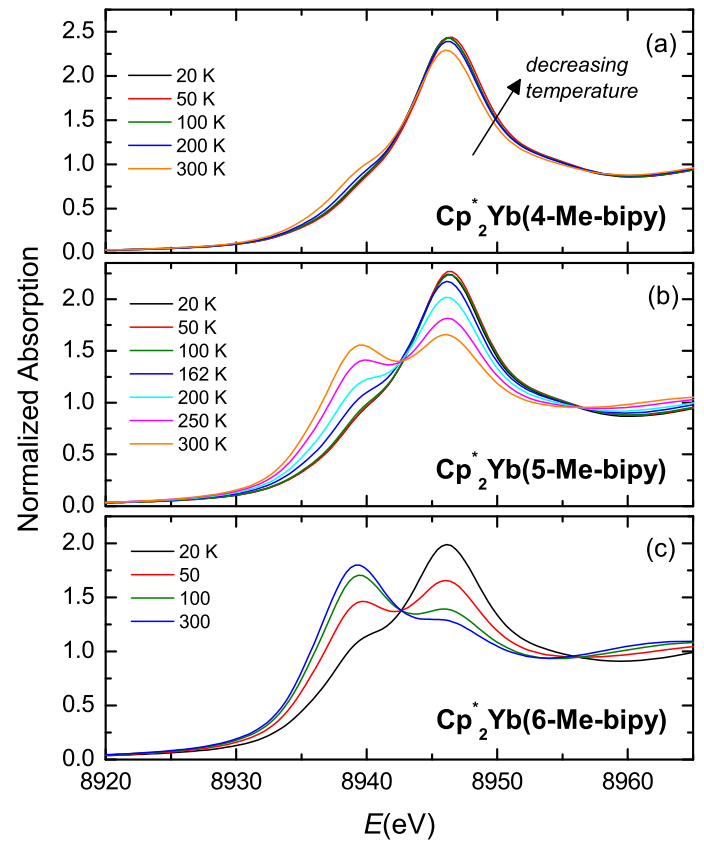

Figure 3: $\mathrm{Yb} L_{\mathrm{III}}$-edge XANES data for $\mathrm{Cp}_{2}^{*} \mathrm{Yb}(\mathrm{x}-\mathrm{Me}$-bipy) complexes at various temperatures.

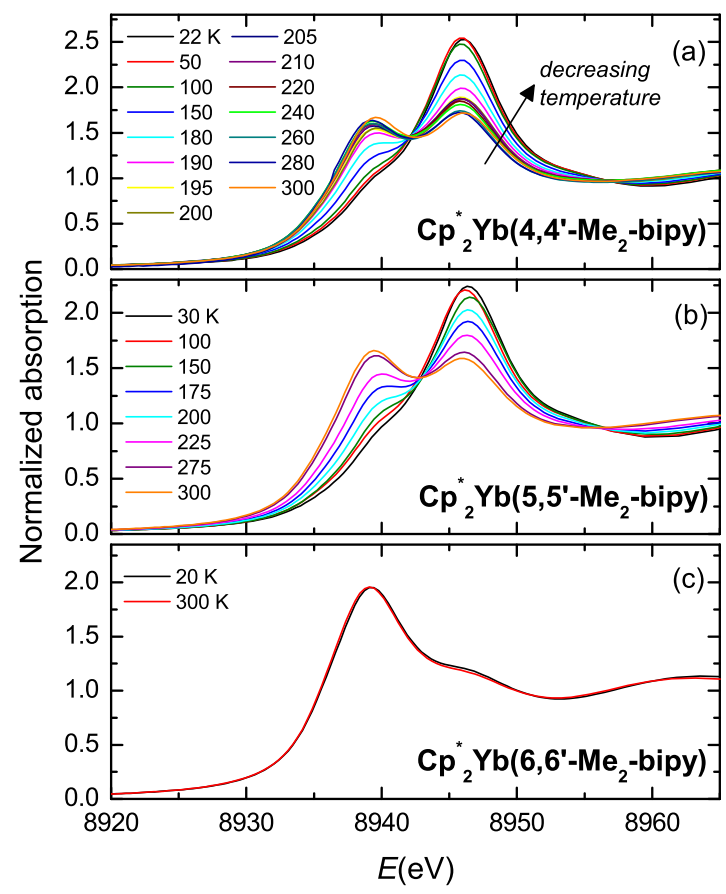

Figure 4: $\mathrm{Yb} L_{\mathrm{III}}$-edge XANES data for $\mathrm{Cp}_{2}^{*} \mathrm{Yb}\left(\mathrm{x}, \mathrm{x}^{\prime}-\mathrm{Me}_{2}\right.$-bipy) complexes at various temperatures. 


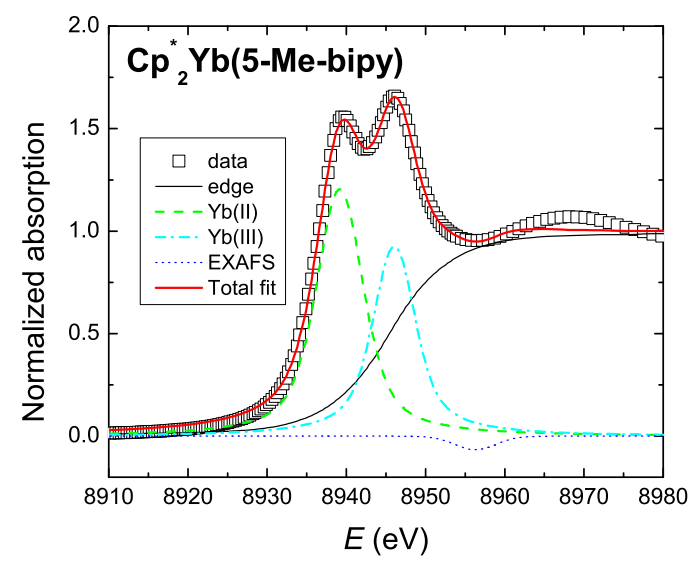

Figure 5: Example of fitting XANES data with pseudo-Voigt peaks.

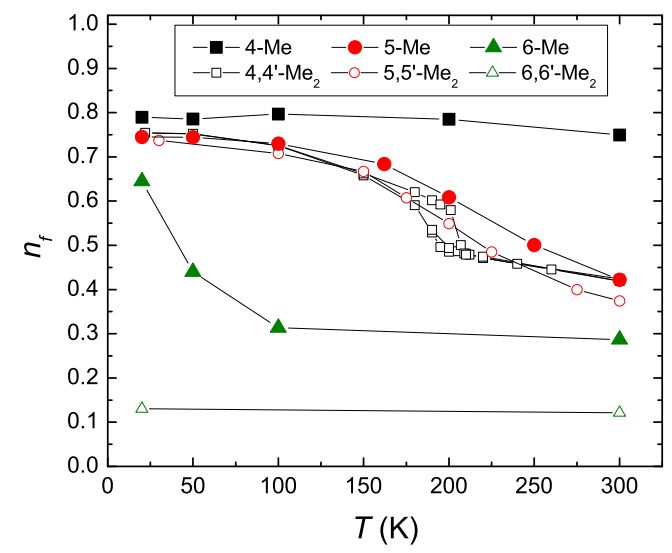

Figure 6: Values of the f-hole occupancy $n_{\mathrm{f}}$ for all Me-substituted bipy adducts to $\mathrm{Cp}_{2}^{*} \mathrm{Yb}$. Results on $\mathrm{Cp}_{2}^{*} \mathrm{Yb}\left(4,4^{\prime}-\mathrm{Me}_{2}\right.$-bipy) are also displayed in Figure 7. 


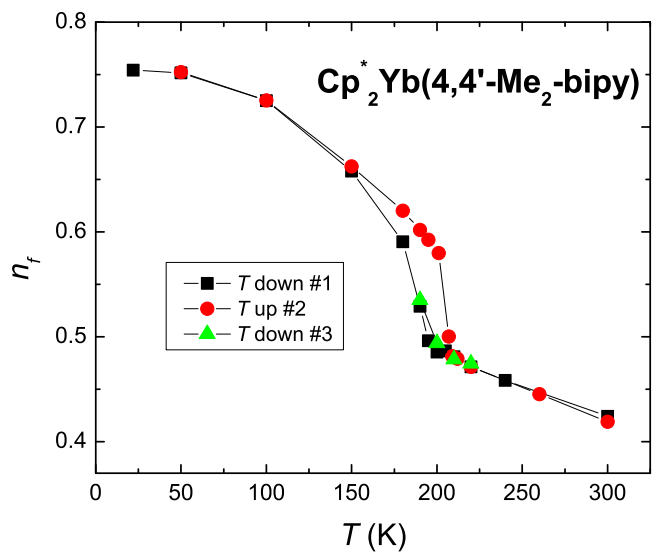

Figure 7: Resulting values of $n_{\mathrm{f}}$ for data from $\mathrm{Cp}_{2}^{*} \mathrm{Yb}\left(4,4^{\prime}-\mathrm{Me}_{2}\right.$-bipy). Note the hysteresis between cooling and heating cycles.
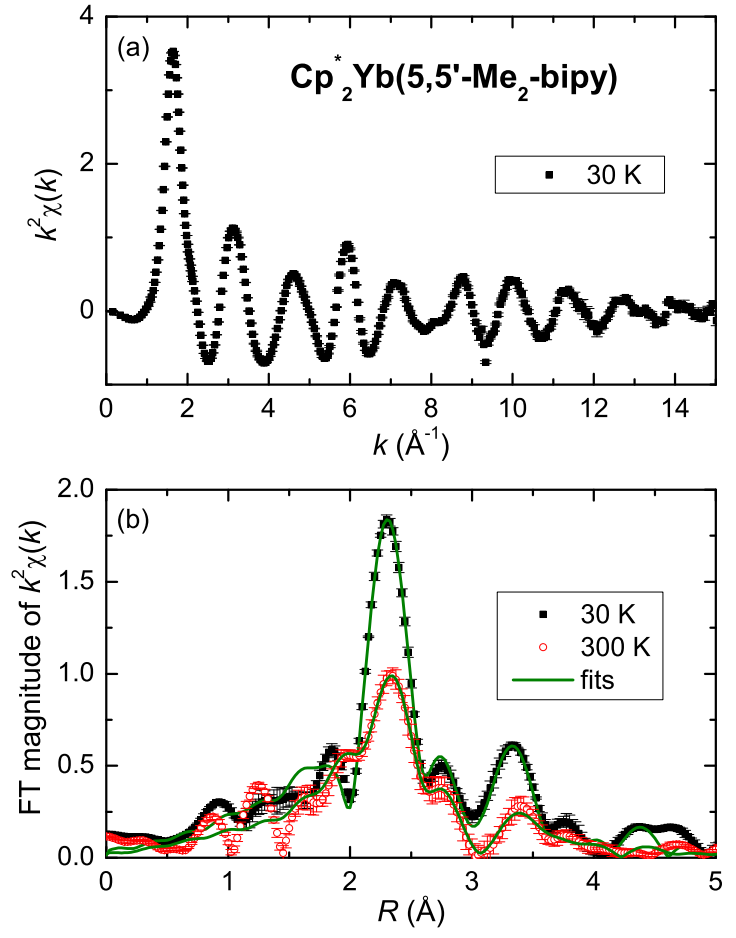

Figure 8: Example of EXAFS data in both (a) $k$-space and (b) $r$-space, where the magnitude of the Fourier Transform (FT) of $k^{2} \chi(k)$ is shown at two temperatures. Also shown in panel (b) are the fits to these data. 
Table 3: EXAFS fit results for $\mathrm{Cp}_{2}^{*} \mathrm{Yb}(\mathrm{x}-\mathrm{Me}-\mathrm{bipy})$ complexes.

\begin{tabular}{|c|c|c|c|c|c|c|c|c|c|}
\hline \multirow[b]{2}{*}{ pair } & \multirow[b]{2}{*}{$N$} & \multicolumn{2}{|c|}{ 4-Me $(30 \mathrm{~K})$} & \multicolumn{2}{|c|}{$4-\mathrm{Me}(300 \mathrm{~K})$} & \multicolumn{2}{|c|}{ 5-Me $(30 \mathrm{~K})$} & \multicolumn{2}{|c|}{ 6-Me $(30 \mathrm{~K})$} \\
\hline & & $\sigma^{2}\left(\AA^{2}\right)$ & $R(\AA)$ & $\sigma^{2}\left(\AA^{2}\right)$ & $R(\AA)$ & $\sigma^{2}\left(\AA^{2}\right)$ & $R(\AA)$ & $\sigma^{2}\left(\AA^{2}\right)$ & $R(\AA)$ \\
\hline $\mathrm{Yb}-\mathrm{N}$ & 2 & $0.003(1)$ & $2.32(1)$ & $0.005(1)$ & $2.329(8)$ & $0.0021(9)$ & $2.329(8)$ & $0.0028(9)$ & $2.364(8)$ \\
\hline $\mathrm{Yb}-\mathrm{C}(\mathrm{Cp})$ & 10 & $0.0029(3)$ & $2.638(6)$ & $0.0063(3)$ & $2.652(4)$ & $0.0031(3)$ & $2.646(5)$ & $0.0038(3)$ & $2.668(3)$ \\
\hline $\mathrm{Yb}-\mathrm{C}\left(2,2-6,6^{\prime}\right)$ & 4 & $0.003(2)$ & $3.24(1)$ & $0.010(3)$ & $3.23(1)$ & $0.003(1)$ & $3.25(1)$ & $0.004(1)$ & $3.27(1)$ \\
\hline $\mathrm{Yb}-\mathrm{C}(\mathrm{Cp}-\mathrm{Me})$ & 10 & $0.006(1)$ & $3.654(9)$ & $0.011(1)$ & $3.672(7)$ & $0.0051(9)$ & $3.655(7)$ & $0.0060(9)$ & $3.685(8)$ \\
\hline $\mathrm{Yb}-\mathrm{C}\left(5,5^{\prime}\right)$ & 4 & $0.001(1)$ & $4.69(2)$ & $0.002(1)$ & $4.70(1)$ & $0.001(1)$ & $4.68(1)$ & $0.002(2)$ & $4.72(2)$ \\
\hline $\mathrm{Yb}-\mathrm{H} / \mathrm{MS}$ & & $0.002(2)$ & $3.64(3)$ & $0.002(2)$ & $3.68(1)$ & $0.002(2)$ & $3.63(2)$ & $0.01(1)$ & $3.62(2)$ \\
\hline$N(\mathrm{Yb}-\mathrm{H} / \mathrm{MS})$ & & \multicolumn{2}{|c|}{$1.5(4)$} & \multicolumn{2}{|c|}{$1.1(2)$} & \multicolumn{2}{|c|}{$1.4(4)$} & \multicolumn{2}{|c|}{$1.7(6)$} \\
\hline$\Delta E_{0}$ & & \multicolumn{2}{|c|}{$-13.8(12)$} & \multicolumn{2}{|c|}{$-14.4(8)$} & \multicolumn{2}{|c|}{$-14.2(10)$} & \multicolumn{2}{|c|}{$-14.3(8)$} \\
\hline$R(\%)$ & & \multicolumn{2}{|c|}{9.53} & \multicolumn{2}{|c|}{5.63} & \multicolumn{2}{|c|}{7.82} & \multicolumn{2}{|c|}{7.02} \\
\hline
\end{tabular}


Table 4: EXAFS fit results for $\mathrm{Cp}_{2}^{*} \mathrm{Yb}\left(\mathrm{x}, \mathrm{x}^{\prime}-\mathrm{Me}_{2}\right.$-bipy) complexes.

\begin{tabular}{|c|c|c|c|c|c|c|c|c|c|}
\hline \multirow[b]{2}{*}{ pair } & \multirow[b]{2}{*}{$N$} & \multicolumn{2}{|c|}{$4,4^{\prime}(20 \mathrm{~K})$} & \multicolumn{2}{|c|}{$4,4^{\prime}(300 \mathrm{~K})$} & \multicolumn{2}{|c|}{$5,5^{\prime}(20 \mathrm{~K})$} & \multicolumn{2}{|c|}{$6,6^{\prime}(20 \mathrm{~K})$} \\
\hline & & $\sigma^{2}\left(\AA^{2}\right)$ & $R(\AA)$ & $\sigma^{2}\left(\AA^{2}\right)$ & $R(\AA)$ & $\sigma^{2}\left(\AA^{2}\right)$ & $R(\AA)$ & $\sigma^{2}\left(\AA^{2}\right)$ & $R(\AA)$ \\
\hline $\mathrm{Yb}-\mathrm{N}$ & 2 & $0.004(2)$ & $2.34(1)$ & $0.020(9)$ & $2.45(4)$ & $0.003(1)$ & $2.33(1)$ & $0.003(1)$ & $2.51(1)$ \\
\hline $\mathrm{Yb}-\mathrm{C}(\mathrm{Cp})$ & 10 & $0.0027(3)$ & $2.654(9)$ & $0.0069(6)$ & $2.710(7)$ & $0.0030(3)$ & $2.650(6)$ & $0.0044(4)$ & $2.737(7)$ \\
\hline $\mathrm{Yb}-\mathrm{C}\left(2,2^{\prime}-6,6^{\prime}\right)$ & 4 & $0.01(1)$ & $3.26(3)$ & $0.010(3)$ & $2.94(2)$ & $0.006(4)$ & $3.25(2)$ & $0.006(2)$ & $3.40(1)$ \\
\hline $\mathrm{Yb}-\mathrm{C}(\mathrm{Cp}-\mathrm{Me})$ & 10 & $0.005(1)$ & $3.67(1)$ & $0.018(6)$ & $3.78(2)$ & $0.0038(9)$ & $3.66(0)$ & $0.008(1)$ & $3.766(8)$ \\
\hline $\mathrm{Yb}-\mathrm{C}\left(5,5^{\prime}\right)$ & 4 & $0.0000(2)$ & $4.70(2)$ & $0.009(7)$ & $4.78(5)$ & $0.000(1)$ & $4.70(2)$ & $0.0000(3)$ & $4.81(1)$ \\
\hline $\mathrm{Yb}-\mathrm{H} / \mathrm{MS}$ & & $0.0000(1)$ & $3.67(3)$ & $0.010(8)$ & $3.71(1)$ & $0.0000(6)$ & $3.65(3)$ & $0.006(9)$ & $3.70(1)$ \\
\hline$N(\mathrm{Yb}-\mathrm{H} / \mathrm{MS})$ & & 1.7 & & 3( & & 1.2 & & & \\
\hline$\Delta E_{0}$ & & -14.3 & (13) & -14.6 & (15) & -15.0 & (13) & -10 . & (17) \\
\hline$R(\%)$ & & 8. & & 6. & & 8. & & 6 & \\
\hline
\end{tabular}


Table 5: EXAFS fit results for $\mathrm{Cp}_{2}^{*} \mathrm{Yb}\left(5,5^{\prime}-\mathrm{Me}_{2}\right.$-bipy) as a function of temperature.

\begin{tabular}{|c|c|c|c|c|c|c|c|c|c|}
\hline \multirow[b]{2}{*}{ pair } & \multirow[b]{2}{*}{$N$} & \multicolumn{2}{|c|}{$30 \mathrm{~K}$} & \multicolumn{2}{|c|}{$150 \mathrm{~K}$} & \multicolumn{2}{|c|}{$225 \mathrm{~K}$} & \multicolumn{2}{|c|}{$300 \mathrm{~K}$} \\
\hline & & $\sigma^{2}\left(\AA^{2}\right)$ & $R(\AA)$ & $\sigma^{2}\left(\AA^{2}\right)$ & $R(\AA)$ & $\sigma^{2}\left(\AA^{2}\right)$ & $R(\AA)$ & $\sigma^{2}\left(\AA^{2}\right)$ & $R(\AA)$ \\
\hline $\mathrm{Yb}-\mathrm{N}$ & 2 & $0.003(1)$ & $2.33(1)$ & $0.002(1)$ & $2.336(8)$ & $0.003(1)$ & $2.35(1)$ & $0.003(1)$ & $2.41(1)$ \\
\hline $\mathrm{Yb}-\mathrm{C}(\mathrm{Cp})$ & 10 & $0.0030(3)$ & $2.650(6)$ & $0.0040(3)$ & $2.651(6)$ & $0.0062(6)$ & $2.635(8)$ & $0.008(1)$ & $2.65(2)$ \\
\hline $\mathrm{Yb}-\mathrm{C}\left(2,2^{\prime}-6,6^{\prime}\right)$ & 4 & $0.006(4)$ & $3.25(2)$ & $0.007(3)$ & $3.25(1)$ & $0.009(2)$ & $3.21(2)$ & $0.008(4)$ & $3.23(5)$ \\
\hline $\mathrm{Yb}-\mathrm{C}(\mathrm{Cp}-\mathrm{Me})$ & 10 & $0.0038(9)$ & $3.66(0)$ & $0.006(1)$ & $3.663(8)$ & $0.009(1)$ & $3.65(1)$ & $0.010(2)$ & $3.67(1)$ \\
\hline $\mathrm{Yb}-\mathrm{C}\left(5,5^{\prime}\right)$ & 4 & $0.000(1)$ & $4.70(2)$ & $0.001(1)$ & $4.70(2)$ & $0.006(3)$ & $4.65(3)$ & $0.005(4)$ & $4.68(3)$ \\
\hline $\mathrm{Yb}-\mathrm{H} / \mathrm{MS}$ & & $0.0000(6)$ & $3.65(3)$ & $0.004(6)$ & $3.64(2)$ & $0.02(1)$ & $3.57(3)$ & $0.01(1)$ & $3.54(7)$ \\
\hline$N(\mathrm{Yb}-\mathrm{H} / \mathrm{MS})$ & & & & & & & & 4( & \\
\hline$\Delta E_{0}$ & & $-15 .($ & (13) & -14 & (13) & -8.9 & 19) & -6.9 & 16) \\
\hline$R(\%)$ & & 8. & & 7. & & 6 & & 7. & \\
\hline
\end{tabular}




\section{Results: Computational}

The calculated complexes $\mathrm{Cp}_{2}^{*} \mathrm{Yb}$ (x-Me-bipy), where $\mathrm{x}=4,5,6$, are all relatively close to having 13 f-electrons, consistent with the low-temperature XANES measurements (Figure 6). In addition, the calculated triplet geometries are close to the experimental ones. For instance, the calculated Yb-N distances are found to be $2.35 \AA$ for the 4-Me and 5-Me complexes and $2.36 \AA$ for the 6Me complex. These results are in good agreement with the EXAFS average distances at $30 \mathrm{~K}$, namely $2.32 \AA$ for the 4-Me, $2.33 \AA$ for the 5-Me and $2.37 \AA$ for the 6-Me (Table 3), although the measured ground states are all less than the calculated triplet $n_{\mathrm{f}}=1$. Note that $n_{\mathrm{f}}$ increases rapidly with decreasing temperature for 6-Me-bipy and is approximately 0.65 at $30 \mathrm{~K}$ (Figure 6), indicating the ground state $n_{\mathrm{f}}$ has not been achieved. Since, the experimental Yb-N bond length was obtained with a lower $n_{\mathrm{f}}$ than that of the ground state, this bond length is expected to be longer than the calculated one, as observed. Similarly, the average $\mathrm{Yb}-\mathrm{C}(\mathrm{Cp})$ distances are in good agreement with the experimental values; $2.66 \AA$ vs. $2.64 \AA$ for the $4-\mathrm{Me}, 2.66 \AA$ vs. $2.65 \AA$ for the 5-Me and 2.69 $\AA$ vs. $2.67 \AA$ for the 6-Me. The agreement is expected to be better than for the $\mathrm{Yb}-\mathrm{N}$ distances, since the $\mathrm{Yb}-\mathrm{C}(\mathrm{Cp})$ distance is less sensitive to $n_{\mathrm{f}}$ than the $\mathrm{Yb}-\mathrm{N}$ distance, as discussed in Section 5. Thus, the experimentally determined distances in the complexes are reproduced by these calculational methods.

Based on these optimized geometries, the nature of the ground state and the first excited state has been investigated at the CASSCF level. The methodology is similar to that used in an earlier calculation on $\mathrm{Cp}_{2} \mathrm{Yb}$ (bipy), ${ }^{12}$ but several improvements have been applied. The first improvement is that $\mathrm{Cp}^{*}$ is explicitly used, rather than $\mathrm{Cp}$. The second, and more important, improvement is that the active space has been expanded to include more $\pi^{*}$ orbitals of the bipy ligand.

The empty $\pi^{*}$ orbitals of bipyridine with symmetry labels in $C_{2 v}$ symmetry are shown in Figure 9. The energies of these orbitals increase ${ }^{38}$ in the order $\pi_{1}^{*} \ll \pi_{2}^{*} \lesssim \pi_{3}^{*} \ll \pi_{4}^{*}$; this order has been verified for both the free and the coordinated ligand. It has also been verified that the presence of the methyl group at any position on the ligand does not modify the relative order of these four orbitals. The earlier calculation ${ }^{12}$ was carried out using only the $\pi_{1}^{*}$ orbital of the bipy ligand with 

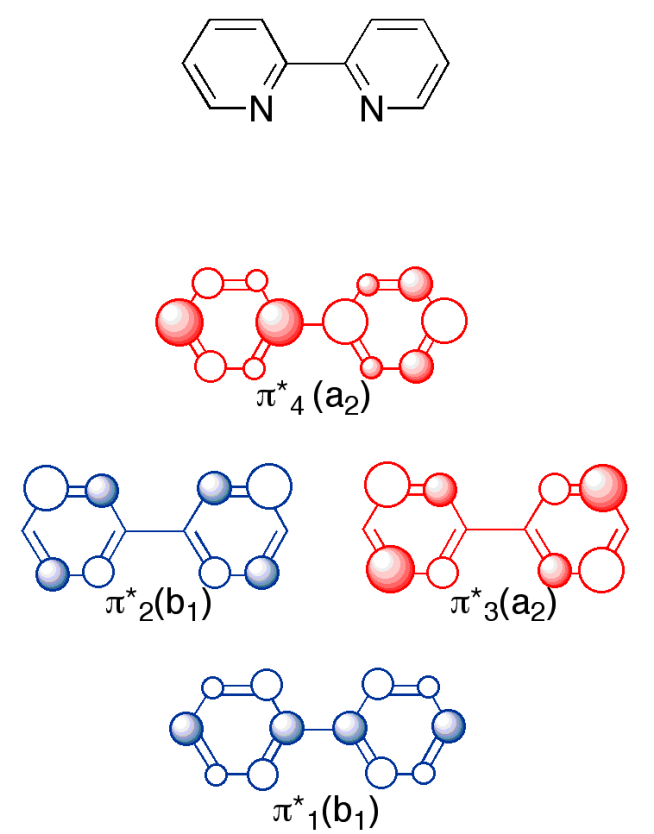

Figure 9: The $\pi^{*}$ orbitals on the bipy ligand in $C_{2 v}$ symmetry. Circle size is proportional to the electron density, and open circles are out of phase with closed circles. Adapted from Ref. 38

$\left(\mathrm{C}_{5} \mathrm{H}_{5}\right)_{2} \mathrm{Yb}$ for the metal fragment. In that calculation, a multiconfigurational open-shell singlet state and the triplet state were found to be within $0.1 \mathrm{eV}$ of each other. Since the singlet state is more likely to be stabilized than the triplet in this system by increasing the active space, we considered this calculational result to be consistent with the multiconfigurational open-shell singlet as the ground state.

The present calculations focus on $\mathrm{Cp}_{2}^{*} \mathrm{Yb}\left(\right.$ bipy $\left.^{\prime}\right)$, where bipy ${ }^{\prime}=4-$ Me-bipy, 5-Me-bipy, and 6-Me-bipy, with bipy $^{\prime}=$ bipy used as a reference. The active space has been increased both by using $\mathrm{Cp}^{*}$ and by including a larger number of the $\pi^{*}$ orbitals. Initial calculations only included the $\pi_{1}^{*}$ and $\pi_{2}^{*}$ orbitals, and then the active space was extended to include the $\pi_{3}^{*}$ orbital, since the $\pi_{2}^{*}$ and $\pi_{3}^{*}$ orbitals are expected to be close together in energy for these systems. In total, the CASSCF calculations were carried out distributing 4 electrons into 5 orbitals ( 2 degenerate $4 \mathrm{f}$, $\pi_{1}^{*}, \pi_{2}^{*}$, and $\pi_{3}^{*}$ ). The main results of these calculations are summarized in Table 6 , Table 7 , and Table 8. An important effect of adding the $\pi_{3}^{*}$ orbital is to push the third-lowest lying singlet state (SS3) well above SS2, as they are nearly degenerate when $\pi_{3}^{*}$ is not included. This effect avoids the so-called "intruder state problem" 33 which otherwise would render these results unusable. ${ }^{39}$ 
Another significant difference is that SS2 is increased by about $+0.2 \mathrm{eV}$ in the 4-Me-bipy complex when $\pi_{3}^{*}$ is included in the active space.

As expected, the lowest-lying singlet ground state now falls well below the triplet state for all calculated complexes. The composition of the ground state singlet for $\mathrm{Cp}_{2}^{*} \mathrm{Yb}$ (bipy) is similar to the previous calculation on $\mathrm{Cp}_{2} \mathrm{Yb}$ (bipy), that is, around $90 \%$ open-shell $\left(80 \% \mathrm{f}^{13}+10 \% \mathrm{f}^{12}\right)$. The composition of the singlet states is calculated to be similar for all Me-bipy's, and are somewhat different than for bipy. For example, SS1 in the Me-bipy's is calculated to be $78 \%$ open shell (59\% $\mathrm{f}^{13}+19 \% \mathrm{f}^{12}$ ) and $22 \%$ closed shell $\left(\mathrm{f}^{14}\right)$, indicating a much larger role for the $\mathrm{f}^{12}$ component. The $\pi_{1}^{*}, \pi_{2}^{*}$, and $\pi_{3}^{*}$ contributions to these states for $\mathrm{Cp}_{2}^{*} \mathrm{Yb}$ (bipy) are given in Table 8 . Due primarily to the loss of symmetry when introducing the Me group onto the bipy ligand, the $\pi_{2}^{*}$ and $\pi_{3}^{*}$ orbitals lose their degeneracy and all of the $\pi^{*}$ orbitals are mixed. Thus, the individual contributions to the configurations cannot be simply determined for these orbitals in the mono-methyl-substituted $\mathrm{Cp}_{2}^{*} \mathrm{Yb}$ (bipy) compounds.

It is important to note that, due to the Brillouin theorem, mixing a configuration with a single electron excitation (e.g., $\mathrm{f}^{13}$ ) into the ground state configuration will not lower the energy of the state. However, mixing of some two-electron, $\mathrm{f}^{12}$, character into the $\mathrm{f}^{13}$ configurations occurs in the present calculations, and the $\mathrm{f}^{12}$ and $\mathrm{f}^{13}$ configurations in these Me-bipy calculations are resonant pairs. In this case, the local electronic density is expected to be nearly that of the nominally $\mathrm{f}^{13}$ configuration, and the two configurations, $\mathrm{f}^{12}$ and $\mathrm{f}^{13}$, should be added when discussing, for instance, the effective valence (f-hole occupancy $n_{\mathrm{f}}$ in Table 7) as it relates to crystallography XANES results.

These calculations have been repeated by including CI at a perturbational level (CASSCFMP2), as shown in Table 6. At the CASSCF level calculations, only one singlet state is below the triplet in $\mathrm{Cp}_{2}^{*} \mathrm{Yb}\left(\right.$ bipy $\left.^{\prime}\right)$. However, the CASSCF-MP2 calculations lower all the singlet states relative to the triplet. In particular, the first excited singlet state drops below the triplet for the 5-Me-bipy and the 6-Me-bipy complexes, but not in the unsubstituted bipy or 4-Me-bipy (Table 6). The state configurations are unchanged by these perturbative calculations (Table 7). 
Table 6: Energy levels $(\mathrm{eV})$ of the four lowest singlet states $\left(\mathrm{SS}^{a}\right)$ relative to the triplet $\left(100 \% \mathrm{f}^{13}\right)$ for each calculated $\mathrm{Cp}_{2}^{*} \mathrm{Yb}(L)$ system.

\begin{tabular}{lllllllll}
\hline & \multicolumn{4}{c}{ CASSCF } & \multicolumn{4}{c}{ CASSCF-MP2 } \\
Ligand & SS1 & SS2 & SS3 & SS4 & SS1 & SS2 & SS3 & SS4 \\
\hline bipy & -0.06 & +0.52 & +1.03 & +2.27 & -0.28 & +0.30 & +0.81 & +2.05 \\
4-Me-bipy & -0.11 & +0.57 & +0.78 & +2.49 & -0.53 & +0.15 & +0.36 & +2.07 \\
5-Me-bipy & -0.08 & +0.39 & +0.66 & +2.51 & -0.58 & -0.11 & +0.16 & +2.01 \\
6-Me-bipy & -0.09 & +0.40 & +1.08 & +2.45 & -0.60 & -0.02 & +0.57 & +1.94 \\
\hline \multicolumn{4}{c}{$a_{\text {see }}$}
\end{tabular}

${ }^{a}$ see Table 7 for state configuration fractions.

Table 7: State configuration fractions ${ }^{a}$ for f-orbitals as calculated by both CASSCF and CASSCFMP2.

\begin{tabular}{ccccc}
\hline Label & $\mathrm{f}^{12}$ & $\mathrm{f}^{13}$ & $\mathrm{f}^{14}$ & $n_{\mathrm{f}}^{b}$ \\
\hline bipy: & & & & \\
SS1 & 0.08 & 0.78 & 0.14 & 0.86 \\
SS2 & 0.21 & 0.13 & 0.66 & 0.34 \\
SS3 & 0.35 & 0.30 & 0.35 & 0.65 \\
SS4 & 0.01 & 0.00 & 0.99 & 0.00 \\
Me-bipy: & & & & \\
SS1 & 0.19 & 0.59 & 0.22 & 0.78 \\
SS2 & 0.15 & 0.10 & 0.75 & 0.25 \\
SS3 & 0.33 & 0.33 & 0.33 & 0.67 \\
SS4 & 0.01 & 0.00 & 0.99 & 0.00 \\
\hline
\end{tabular}

${ }^{a}$ Configuration fractions are rounded to $1 \%$ for configuration $i$, determined from the configuration coefficients $c_{i}$ as $c_{i}^{2} / \sum_{j} c_{j}^{2} \cdot{ }^{b} n_{\mathrm{f}}$ is the sum of the $\mathrm{f}^{12}$ and $\mathrm{f}^{13}$ configuration, see Section 4 .

Table 8: State configuration fractions ${ }^{a}$ for $\pi^{*}$-orbitals for $\mathrm{Cp}_{2}^{*} \mathrm{Yb}(\mathrm{bipy})$ as calculated by both CASSCF and CASSCF-MP2.

\begin{tabular}{cccc}
\hline Label & $\pi_{1}^{*}$ & $\pi_{2}^{*}$ & $\pi_{3}^{*}$ \\
\hline bipy: & & & \\
SS1 & 0.45 & 0.20 & 0.35 \\
SS2 & 0.42 & 0.16 & 0.42 \\
SS3 & 1.00 & 0.00 & 0.00 \\
SS4 & 0.00 & 0.00 & 0.00 \\
\hline
\end{tabular}

${ }^{a}$ Configuration fractions are rounded to $1 \%$ for configuration $i$, determined from the configuration coefficients $c_{i}$ as $c_{i}^{2} / \sum_{j} c_{j}^{2}$. 
The presence of an open-shell singlet ground state is well established by all of these calculations. As an indication of whether a triplet ground state is likely if a larger active space were used, we note that the MP2 diagnostic based on the CASSCF, which indicates the amount of electronic correlation that is outside the CAS, also strongly favors the singlet state. ${ }^{40}$ While, these contributions stabilize both singlet and triplet states, they are therefore much more stabilizing for the singlets.

\section{Discussion}

The magnetic susceptibility data shown in Figure 2 have several features in common. At the lowest temperatures, a rapidly decreasing "tail" is observed as the temperature is increased. This feature is ascribed to a small amount of impurity. ${ }^{12}$ Otherwise, the overall magnitude of $\chi(T)$ is much smaller than expected for such molecules with a trivalent, or partially trivalent $\mathrm{Yb}$ atom. These data are not consistent with any significant susceptibility arising from a triplet configuration, although the triplet may be responsible for the upturn in $\chi(T)$ near room temperature for the $\mathrm{Cp}_{2}^{*} \mathrm{Yb}(4-\mathrm{Me}$ bipy) data. The $\mathrm{Cp}_{2}^{*} \mathrm{Yb}\left(4-\mathrm{Me}\right.$-bipy) data are very similar to data on $\mathrm{Cp}_{2}^{*} \mathrm{Yb}$ (bipy). ${ }^{12}$

The XANES data show a wide range of behavior for the Yb valence, from nearly divalent in $\mathrm{Cp}_{2}^{*} \mathrm{Yb}\left(6,6^{\prime}-\mathrm{Me}_{2}\right.$-bipy) to trivalent in $\mathrm{Cp}_{2}^{*} \mathrm{Yb}(4-\mathrm{Me}$-bipy) at all temperatures, to those transitioning between these states as a function of temperature and position of the methyl group in the bipyridine ring. It is important to note, however, that neither a pure divalent nor a pure trivalent $\mathrm{Yb}$ state is

observed for any of these neutral complexes. ${ }^{41}$ These data therefore indicate mixed valence for all measured samples.

Of central interest is whether this mixed valence is homogeneous, as in the IV state described in the Introduction, or heterogeneous, as when one of various valence states occurs at different locations in a compound, as in $\mathrm{Fe}_{3} \mathrm{O}_{4}$, or in spin-equilibrium tautomers, such as the $\mathrm{Fe}(\mathrm{III})$ spin transition complexes. ${ }^{42}$ This question is answered best by the structural data, although the conclusion of intermediate valence is supported by the magnetic data, which are inconsistent with a 
heterogeneous mixed valence model. ${ }^{12}$ Regardless, the degree of heterogeneity can be determined from temperature-dependent results for site positions or bond lengths, together with mean-squared displacement parameters. Here, we focus on the $\mathrm{Yb}-\mathrm{N}$ and $\mathrm{Yb}-\mathrm{C}(\mathrm{Cp})$ bonds. Each of these bond lengths is well determined by both EXAFS and single-crystal XRD. Table 9 compares some of the available structural data between these techniques. Discrepancies only arise where the available data were collected at different temperatures for the two techniques, and is fully consistent with the observed changes in valence with temperature (Figure 6). $\mathrm{Yb}-\mathrm{N}$ and $\mathrm{Yb}-\mathrm{C}(\mathrm{Cp})$ bond length data are shown in Figure 10 as a function of $n_{\mathrm{f}}$, combining available EXAFS and XRD results. These data indicate that the measured bond lengths are roughly linear with $n_{\mathrm{f}}$, and that the difference in $\mathrm{Yb}-\mathrm{N}$ bond lengths between $\mathrm{Yb}(\mathrm{II})$ and $\mathrm{Yb}(\mathrm{III})$ in this class of compounds is about $0.3 \AA$. In the case of heterogeneous mixed valence, one therefore expects a distribution of $\mathrm{Yb}(\mathrm{II})-\mathrm{N}$ and $\mathrm{C}(\mathrm{Cp})$ bond lengths corresponding to the measured $n_{\mathrm{f}}$. Since the EXAFS fits group all the $\mathrm{Yb}-\mathrm{N}$ and $\mathrm{Yb}-\mathrm{C}(\mathrm{Cp})$ paths into single shells near $2.4 \AA$ and $2.7 \AA$, respectively, such a heterogeneous mixedvalence situation would result in an enhancement of the mean-squared displacement parameter, $\sigma^{2}$, for the Yb-N pairs corresponding to about $0.016 \AA^{2}$ for all the samples with $n_{\mathrm{f}} \approx 0.75$. Such a large $\sigma^{2}(\mathrm{Yb}-\mathrm{N})$ value is inconsistent with the measured samples, which all have $\sigma^{2}(\mathrm{Yb}-\mathrm{N}) \approx 0.003(1)$ $\AA^{2}$. The enhancement for the $\sigma^{2}(\mathrm{Yb}-\mathrm{C}(\mathrm{Cp}))$ would actually be much smaller (around $0.003 \AA^{2}$ ), and so is less useful in this regard.

We emphasize here that the EXAFS technique is very reliable for determining local disorder in the nearest-neighbor shells, even in cases where diffraction sees only an essentially ordered structure. An example occurs in the calcium-doped lanthanum manganites, $\mathrm{La}_{1-x} \mathrm{Ca}_{x} \mathrm{MnO}_{3}$ for $x$ values near 0.3. In this case, careful analysis of powder XRD data indicates small values of the single-site mean-squared displacements with only small changes near the ferromagnetic transition, ${ }^{43}$ while local structure probes such as PDF $^{44}$ and EXAFS ${ }^{45}$ obtain $\sigma^{2}$ values consistent in magnitude with a fully-formed Jahn-Teller distortion around the Mn(III) ions. In this case, XRD does not get the same result because it measures displacements from mean positions of individual sites, and the powder average washes the effect away. In contrast, EXAFS averages over pairs of atoms. In 


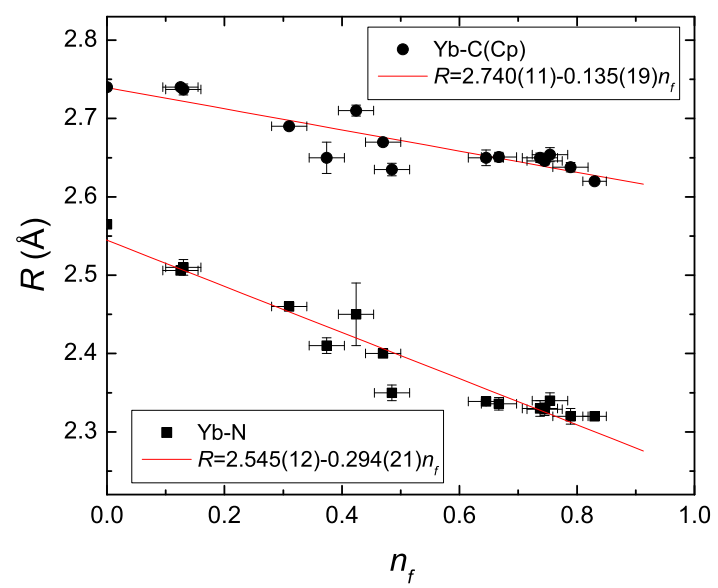

Figure 10: Average pair distances for the $\mathrm{Yb}-\mathrm{N}$ and $\mathrm{Yb}-\mathrm{C}(\mathrm{Cp})$ bonds as a function of $n_{\mathrm{f}}$. Most of these values are from EXAFS data, but some are from single-crystal x-ray diffraction.

Table 9: EXAFS bond length results for selected data.

\begin{tabular}{lccc}
\hline Ligand & $T_{\text {EXAFS }}$ & Yb-N avg. & Yb-C(Cp) avg. \\
\hline 6-Me bipy & $20 \mathrm{~K}$ & $2.364(8)$ & $2.668(3)$ \\
4,4'-Me bipy & $300 \mathrm{~K}$ & $2.45(4)$ & $2.710(7)$ \\
$5,5^{\prime}$-Me bipy & $150 \mathrm{~K}$ & $2.336(8)$ & $2.656(6)$ \\
6,6'-Me bipy & $20 \mathrm{~K}$ & $2.51(1)$ & $2.737(7)$ \\
\hline
\end{tabular}

addition, diffraction occurs most readily on well ordered parts of a sample, so it can miss disorder in mixed materials, while EXAFS data represent a true average over all the absorbing atom within the x-ray beam path.

The $\mathrm{Cp}_{2}^{*} \mathrm{Yb}\left(5,5^{\prime}-\mathrm{Me}_{2}\right.$-bipy) data provide an interesting test case, as these data were also collected as a function of temperature (Table 5). Since this compound demonstrates large changes in valence with temperature (Figure 6), if it were heterogeneously mixed valent, the $\sigma_{\mathrm{Yb}-\mathrm{N}}^{2}$ and $\sigma_{\mathrm{Yb}-\mathrm{C}(\mathrm{Cp})}^{2}$ parameters would follow the changes in valence, since the relative ratio of $\mathrm{Yb}(\mathrm{II})$ and $\mathrm{Yb}$ (III) bonds would be varying. Therefore, if this compound were heterogeneous mixed valent, we would expect $\sigma_{\mathrm{Yb}-\mathrm{N}}^{2}$ to be on the order of $0.016 \AA^{2}$, to increase by about $0.004 \AA^{2}$ near $n_{\mathrm{f}} \approx 0.5$ ( $T \approx 225 \mathrm{~K}$ ), and then to decrease slightly with temperature. None of these predictions are compatible with the data in Table 5. In particular, the $\sigma^{2}$ values for the $\mathrm{Yb}-\mathrm{N}$ pair remain small at all temperatures, near $0.003(1) \AA^{2}$. The changes in $\sigma_{\mathrm{Yb}-\mathrm{C}(\mathrm{Cp})}^{2}$ likewise do not follow $n_{\mathrm{f}}$, but rather 
increase monotonically with $T$, as expected from thermal vibrations. In fact, the $\sigma^{2}$ data are well described by an Einstein model ${ }^{46}$ of the thermal vibrations, with $\Theta_{E}>500 \mathrm{~K}$ for $\mathrm{Yb}-\mathrm{N}$ and $\Theta_{E}=250(20) \mathrm{K}$ for $\mathrm{Yb}-\mathrm{C}(\mathrm{Cp})$, although one must assume no static distortion and that the carbon atoms in the $\mathrm{Cp}$ rings are tightly bound, and therefore, the effective mass of each carbon is about three times that of a free carbon. A similar situation occurs in the lanthanide hexaborides. ${ }^{47} \mathrm{We}$ therefore conclude that $\mathrm{Yb}$ in these molecules is homogeneously mixed valent, that is, intermediate valent (IV).

The most striking experimental result is the temperature dependence of $n_{\mathrm{f}}$ in $\mathrm{Cp}_{2}^{*} \mathrm{Yb}(5-\mathrm{Me}-$ bipy), $\mathrm{Cp}_{2}^{*} \mathrm{Yb}(6-\mathrm{Me}-\mathrm{bipy}), \mathrm{Cp}_{2}^{*} \mathrm{Yb}\left(5,5^{\prime}-\mathrm{Me}_{2}\right.$-bipy $)$, and $\mathrm{Cp}_{2}^{*} \mathrm{Yb}\left(6,6^{\prime}-\mathrm{Me}_{2}\right.$-bipy $)$. These data can be fit with a Boltzmann distribution describing an excitation from a singlet ground state to a singlet excited state with a different characteristic $n_{\mathrm{f}}$ :

$$
n_{\mathrm{f}}(T)=\frac{n_{g S}+n_{e x} e^{\frac{-(\Delta H-T \Delta S)}{R T}}}{1+e^{\frac{-(\Delta H-T \Delta S)}{R T}}},
$$

where $n_{g s}$ is the $n_{\mathrm{f}}$ in the ground state, $n_{e x}$ is the $n_{\mathrm{f}}$ in the excited state, $\Delta H$ is the change in enthalpy, $\Delta S$ is the change in entropy, and $R$ is the universal gas constant. Figure 11 shows fits to Eq. (2) for the relevant $n_{\mathrm{f}}$ data, and the fit parameters are reported in Table 10. Besides the good quality of the fit, the most significant result is that $n_{e x}$ does not go to zero; that is, $n_{\mathrm{f}}$ of the first excited state is multiconfigurational. Note this result holds even for the $\mathrm{Cp}_{2}^{*} \mathrm{Yb}(6-\mathrm{Me}-\mathrm{bipy})$ data, where the availability of only four data points prevents the calculation of error bars in the unweighted fit with Eq. (2), since a fit holding $n_{e x} \equiv 0$ is not of acceptable quality.

The susceptibility data for the 5-, 6-, 4,4'-, and 5,5'-Me-bipy complexes are fully consistent with a similar Boltzmann distribution, in this case, between a ground state and an excited state that are each TIP:

$$
\chi(T)=\frac{\chi_{g s}+\chi_{e x} e^{\frac{-(\Delta H-T \Delta S)}{R T}}}{1+e^{\frac{-(\Delta H-T \Delta S)}{R T}}}+C_{\mathrm{imp}} / T
$$

where $C_{\mathrm{imp}} / T$ is the Curie-tail impurity contribution. Fit parameters are summarized in Table 10. Note that depending on the data available, some parameters were held fixed in these fits, and are 


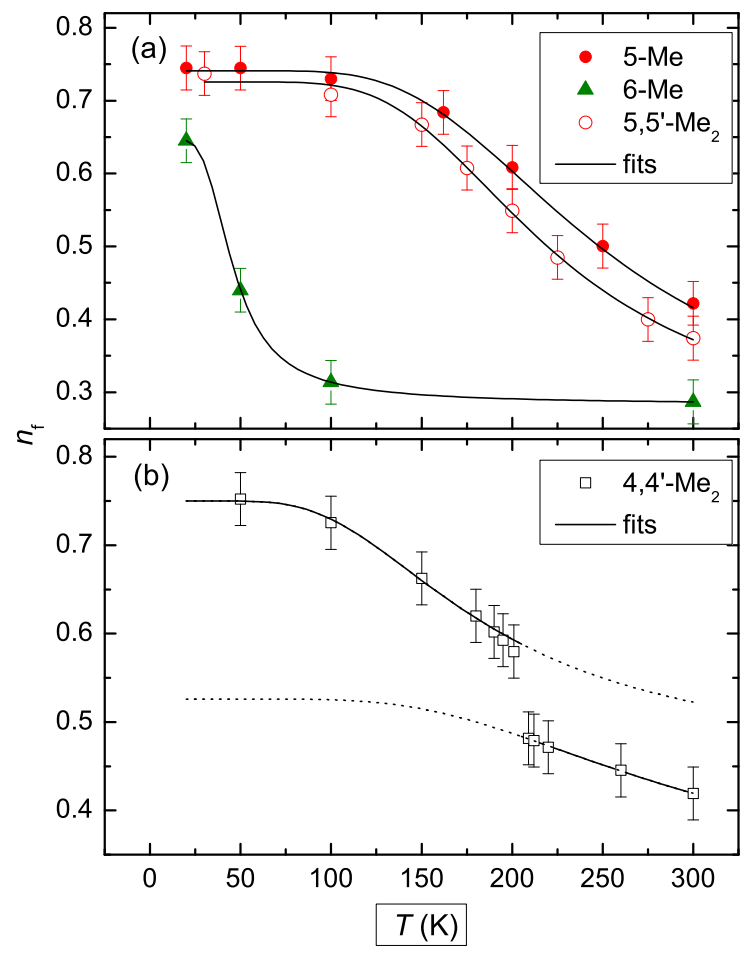

Figure 11: Boltzmann fits (Eq. (2)) to selected data. See Table 10 for fit parameters.

thus reported with no estimated error. The error on such parameters is otherwise large, except for the fits to $n_{\mathrm{f}}$ from the 6-Me-bipy data, as noted above. We view the negative estimated values of $\chi_{e x}$ for $\mathrm{Cp}_{2}^{*} \mathrm{Yb}\left(5-\mathrm{Me}\right.$-bipy) and $\mathrm{Cp}_{2}^{*} \mathrm{Yb}\left(5,5^{\prime}-\mathrm{Me}_{2}\right.$-bipy) to be consistent with a small, but positive, magnetic susceptibility for the excited state, given the large error estimate. We also note that small weighing errors, systematic errors from the magnetometer, imperfect diamagnetic corrections, etc., could contribute to such an unphysical, negative result.

The impurity contribution from these fits should be compared to the full $J=7 / 2$ Curie constant expected for $\mathrm{Yb}(\mathrm{III})$ of $2.57 \mathrm{emu} / \mathrm{mol}$, or much larger if the impurity is from some magnetic phase of iron. Therefore, if the impurity is due to some small amount of hydrolysis contamination, it represents no more than $2 \%$ of the ytterbiums in the sample. These tails are not reproducible from sample to sample, and so are not intrinsic.

Although the agreement between fits to $n_{\mathrm{f}}$ and $\chi$ data is not exact, given the simplicity of the model and the size of certain estimated errors, the similar values of $\Delta H$ and $\Delta S$ between these 


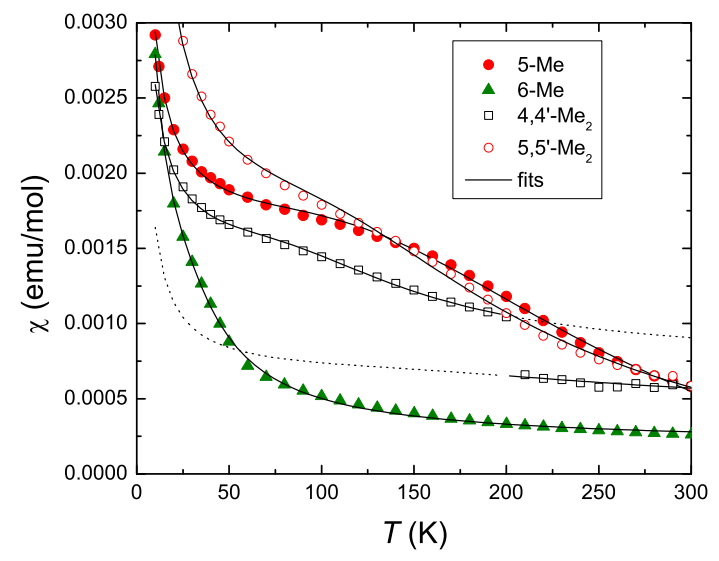

Figure 12: Boltzmann fits (Eq. (3)) to selected susceptibility data. See Table 10 for fit parameters.

fits indicates the changes with temperature of both kinds of data are due to the same Boltzmann distribution of state occupancies. In particular, the changes in entropy are small, as expected for a transition between two singlet states, and are probably dominated by differences in vibrational entropy. For comparison, heat capacity measurements in Fe(III) spin transition complexes find $\Delta S_{\mathrm{vib}} \approx 30 \mathrm{~J} \mathrm{~mol}^{-1} \mathrm{~K}^{-1} .42$

One interesting result is that the 4-Me-bipy and bipy complexes cannot be fit with the model in Eq. (3). Instead, a model where the first excited state is a triplet with Curie-Weiss paramagnetism can provide an excellent fit (available as Supporting Information). These fits therefore strongly support the order of states indicated by the CASSCF-MP2 calculations in Table 6.

The data from $\mathrm{Cp}_{2}^{*} \mathrm{Yb}\left(4,4^{\prime}-\mathrm{Me}_{2}\right.$-bipy) are particularly interesting, since the previously observed transition near $200 \mathrm{~K}$ in the magnetic susceptibility ${ }^{19}$ is now clearly associated with a valence transition. When originally observed, it was noted that $\mathrm{Cp}_{2}^{*} \mathrm{Yb}\left(4,4^{\prime}-\mathrm{Me}_{2}\right.$-bipy)'s space group in the high-temperature state, $P 2_{1} / c$, is unusual for this class of compounds, which are generally $P b c a$. The only other exceptions occur when some solvent is crystallized into the structure, such as for $\mathrm{Cp}_{2}^{*} \mathrm{Yb}\left(6,6^{\prime}-\mathrm{Me}_{2}\right.$-bipy) (Figure 1), which is not the case for $\mathrm{Cp}_{2}^{*} \mathrm{Yb}\left(4,4^{\prime}-\mathrm{Me}_{2}\right.$-bipy). It is reasonable to conjecture that the observed increase in the valence (Figure 7) as the temperature is decreased from room temperature will act as increasing pressure, consistent with the decreasing volume, ${ }^{19}$ until such point that the $P 2_{1} / c$ structure can no longer support the molecule. At this point, the 
Table 10: Fit results of the SS1 $\rightleftharpoons \mathrm{SS} 2$ equilibrium (Eq. (2) and Eq. (3)) to $n_{\mathrm{f}}(\mathrm{T})$ and $\chi(T)$, as shown in Figure 11 and Figure 12.

\begin{tabular}{lccccccccc}
\hline Ligand & $n_{g s}$ & $n_{e x}$ & $\chi_{g s}^{a}$ & $\chi_{e x}^{a}$ & $\Delta H_{n_{\mathrm{f}}}^{b}$ & $\Delta H_{\chi}^{b}$ & $\Delta S_{n_{\mathrm{f}}}^{c}$ & $\Delta S_{\chi}^{c}$ & $C_{\mathrm{imp}}{ }^{d}$ \\
\hline $5-\mathrm{Me}$ & $0.74(1)$ & $0.2(1)$ & $0.00161(1)$ & $-0.0014(7)$ & $7(1)$ & $5.1(4)$ & $26(7)$ & $12(4)$ & $0.0133(2)$ \\
6-Me & 0.646 & 0.28 & $0.00086(4)$ & $0.00012(3)$ & 1.6 & $1.0(1)$ & 19 & $34(2)$ & $0.0192(5)$ \\
$4,4^{\prime}(\mathrm{LT})^{e}$ & $0.750(4)$ & $0.41(3)$ & $0.00143(1)$ & $0.00065(2)$ & $4.3(3)$ & $3.6(1)$ & $20^{f}$ & $19(2)$ & $0.0116(1)$ \\
$4,4^{\prime}(\mathrm{HT})^{g}$ & $0.53(1)$ & $0.27(3)$ & $0.00064(2)$ & $0.00039(5)$ & $6.9(7)$ & $6.9^{f}$ & $20^{f}$ & $20^{f}$ & 0.01 \\
$5,5^{\prime}$ & $0.726(7)$ & $0.21(9)$ & $0.00157(1)$ & $-0.0004(3)$ & $7(1)$ & $4.5(4)$ & $29(8)$ & $16(4)$ & $0.032(3)$ \\
\hline
\end{tabular}

${ }^{a} \mathrm{emu} / \mathrm{mol} .{ }^{b} \mathrm{~kJ} / \mathrm{mol} .{ }^{c} \mathrm{~J} /(\mathrm{mol} \cdot \mathrm{K}) .{ }^{d} \mathrm{emu} \cdot \mathrm{K} / \mathrm{mol} .{ }^{e}$ Fit to $T \leq 200 \mathrm{~K} .{ }^{f}$ These values were held fixed. ${ }^{g}$ Fit to $T \geq 210 \mathrm{~K}$. 
crystals shatter, and the low temperature structure has not been determined; however, it is unlikely that the molecular form of $\mathrm{Cp}_{2}^{*} \mathrm{Yb}\left(4,4^{\prime}-\mathrm{Me}_{2}\right.$-bipy) is altered in the low temperature state, especially given the consistency between the EXAFS results at $20 \mathrm{~K}$ compared to $300 \mathrm{~K}$ (Table 4). In fact, a pair-distribution function (PDF) analysis of powder x-ray diffraction data through the transition is consistent with the molecule remaining intact. ${ }^{48}$ The structural and magnetic transition can then be viewed as analogous to the Kondo-driven volume changes at isostructural valence transitions in elemental cerium ${ }^{49}$ and $\mathrm{YbInCu}_{4},{ }^{50}$ furthering the analogy to the Kondo effect in such solid-state intermetallic systems.

An important implication of this phase transition is that the environment around the molecule has some effect, as previously pointed out regarding data on $\mathrm{Cp}^{*} 2 \mathrm{La}$ (bipy). ${ }^{12}$ This result is not surprising given the extremely small differences in energy between the ground and excited states, and begs the question of how the intermediate valence states and the Boltzmann distributions will change in solution samples. Such experiments deserve further study, especially on the $\mathrm{Cp}_{2}^{*} \mathrm{Yb}\left(4,4^{\prime}\right.$ $\mathrm{Me}_{2}$-bipy) sample; however, certain experimental challenges in obtaining quality magnetic and $\mathrm{X}$-ray data on such solutions at low temperature have yet to be overcome.

Based on all these experimental data, we make the following deductions. First, the observed mixed valence of $\mathrm{Yb}$ in these molecules indicates intermediate valence at all measured temperatures, although the degree of IV changes with temperature. The magnetometry does not indicate any significant triplet configuration, except perhaps at high temperature in $\mathrm{Cp}_{2}^{*} \mathrm{Yb}(4-\mathrm{Me}-\mathrm{bipy})$, and can in fact be fit as due to an equilibrium between two singlet configurations. The Yb valence can likewise be fit as an equilibrium between two states, with similar changes in enthalpy and entropy found in the susceptibility fits. Therefore, the properties of these molecules are described by two multiconfigurational singlet states, where the ground state is similar to that found in $\mathrm{Cp}_{2}^{*} \mathrm{Yb}(\mathrm{bipy})$ and the excited state is more dominated by the $\mathrm{f}^{14}$ configuration. The $n_{\mathrm{f}}$ of the ground state and first excited state are then given by the Boltzmann fits to $n_{\mathrm{f}}$ (Figure 11), and are roughly 0.70 and 0.25 , respectively, for the Me-substituted compounds, besides $\mathrm{Cp}_{2}^{*} \mathrm{Yb}(4-\mathrm{Me}-\mathrm{bipy})$.

A molecular explanation can be given to the thermodynamic constants between the two states, 


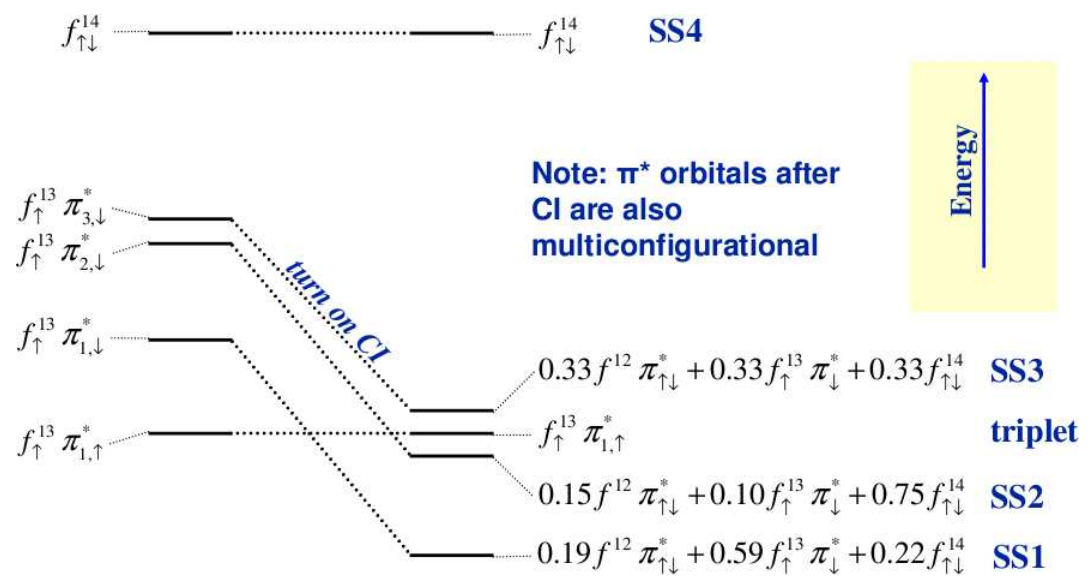

Figure 13: Cartoon energy-level diagram showing the effect of $\mathrm{CI}$ for the $\mathrm{Cp} \mathrm{p}_{2}^{*} \mathrm{Yb}(5-\mathrm{Me}$-bipy) system. On the left are the approximate energy levels of individual configurations for a single-electron theory such as DFT. On the right are the results of the CASSCF-MP2 results as described in Table 6 and Table 7 . As noted the $\pi^{*}$ orbitals on the right hand side are also multiconfigurational (Section 4).

$\mathrm{SS} 1 \rightleftharpoons \mathrm{SS} 2$, shown in Table 10, based on the computational results shown in Table 7. Using the specific example of $\mathrm{Cp}_{2}^{*} \mathrm{Yb}$ (5-Me-bipy), the change in enthalpy favors the SS1 state while the change in entropy favors the SS2 state, with the net result that the temperature at which $\Delta G=0$ is around $240 \sim 280 \mathrm{~K}$. The SS1 state has an f-hole occupancy $n_{\mathrm{f}}=0.78$, which means that $\mathrm{Yb}(\mathrm{III})$ dominates $\mathrm{Yb}(\mathrm{II})$. Since the $\mathrm{Yb}(\mathrm{III})-\mathrm{N}$ and $\mathrm{Yb}(\mathrm{III})-\mathrm{C}$ bond lengths are shorter than the $\mathrm{Yb}(\mathrm{II})$ $\mathrm{N}$ and $\mathrm{Yb}(\mathrm{II})-\mathrm{C}$ bondlengths (Table 2), the $\mathrm{Yb}(\mathrm{III})$ contributions are favored by the enthalpy (or energy), but disfavored by the entropy. Conversely, the contributions of $\mathrm{Yb}(\mathrm{III})$ and $\mathrm{Yb}(\mathrm{II})$ are inverted in the SS2 state, where $n_{\mathrm{f}}=0.25$. Accordingly, the longer $\mathrm{Yb}(\mathrm{II})-\mathrm{N}$ and $\mathrm{Yb}(\mathrm{II})-\mathrm{C}$ bond distances are disfavored by the enthalpy (or energy) and favored by the entropy. The computational studies therefore illuminate the thermochemical measurements by providing a molecular level of understanding.

The CASSCF calculations are in qualitative agreement with these conclusions, indicating two low-lying open-shell singlet states, with $n_{\mathrm{f}}=0.78$ in the ground state and $n_{\mathrm{f}}=0.25$ in the first excited state (compare Table 6 and Table 7 to results in Figure 6 and Figure 11). The situation for $\mathrm{Cp}_{2}^{*} \mathrm{Yb}\left(5,5^{\prime}-\mathrm{Me}_{2}\right.$-bipy) is shown in cartoon form in Figure 13. It is important to note that the errors in the CASSCF calculations are expected to be on the order of $0.3 \mathrm{eV}$, although relative 
errors between states are smaller. With this error in mind (see also below), the CASSCF-MP2 results for the relative energies of the singlet and triplet states are in excellent agreement with the experimental results: all these materials have a singlet ground state, and all have a singlet firstexcited state, except $\mathrm{Cp}_{2}^{*} \mathrm{Yb}$ (bipy) and $\mathrm{Cp}_{2}^{*} \mathrm{Yb}(4-\mathrm{Me}$-bipy), which have a triplet first-excited state. Even though the non-perturbative CASSCF calculations place the triplet at a different position relative to the singlet states, the CASSCF and CASSCF-MP2 calculations are consistent given the estimated errors. In addition, with the improved calculation on the $\mathrm{Cp}_{2}^{*} \mathrm{Yb}$ (bipy) compound, $n_{\mathrm{f}}=0.86$, indicating it should be closer to $\mathrm{Yb}(\mathrm{III})$ than the methyl-substituted bipy complexes, as observed with $n_{\mathrm{f}}=0.83$ from $\mathrm{Yb} L_{\mathrm{III}}$ XANES in $\mathrm{Cp}_{2}^{*} \mathrm{Yb}$ (bipy). ${ }^{12}$ Finally, it should be noted that the CASSCF calculations predict $n_{\mathrm{f}}$ within about $4 \%$ in all cases.

There are limitations to these calculations that must be mentioned. In these CI calculations only one triplet configuration and several singlet configurations are included in the active space, and the relative energy between the singlet and triplet states is not well determined; the singlets can interact to lower the energy of the more stable states, while the triplet state cannot. This inadequacy is a limitation of the CASSCF method, since one must set the size of the active space in a somewhat arbitrary manner by trying to choose the dominant interactions. Therefore, as in the case of $\mathrm{Cp}_{2}^{*} \mathrm{Yb}$ (bipy), if a singlet state is nearly degenerate or slightly below a triplet state, one can say with confidence that the singlet state will be the ground state, since including more interactions will likely further stabilize the singlet relative to the triplet. On the other hand, although CASSCF should properly determine the relative order of the various singlet states, the energy differences can only be considered qualitatively.

Given these limitations, the computational results on the $\mathrm{Cp}_{2}^{*} \mathrm{Yb}(5-\mathrm{Me}-\mathrm{bipy})$ and $\mathrm{Cp} \mathrm{p}_{2}^{*} \mathrm{Yb}(6-\mathrm{Me}-$ bipy) complexes are different from the results on $\mathrm{Cp}_{2}^{*} \mathrm{Yb}$ (bipy) and $\mathrm{Cp}_{2}^{*} \mathrm{Yb}(4-\mathrm{Me}$-bipy) in that the methyl substitution generates a first excited state that is also an open-shell singlet, at least from the CASSCF-MP2 methodology. Accordingly, these calculations show that the first excited state could be thermally populated, as indicated by the experimental results. The trends also reflect the experimental data on the bipy and 4-Me-bipy complexes in which the first excited state is a triplet 
for these two complexes. The experimental and calculational results are therefore in agreement.

Remaining questions include those aimed at developing a physical model that relates these effects, and how they relate to previous known chemistry and physics. Of central importance is understanding the currently-unique role of the methyl substitution, which is considered to be an electron donor in the neutral ligand. Although the increased mixing of $\mathrm{f}^{14}$ character in the ground state relative to $\mathrm{Cp}_{2}^{*} \mathrm{Yb}$ (bipy) is consistent with an electron donor, it may seem counter-intuitive that such a substitution stabilizes the relatively high-lying singlets in the $\mathrm{Cp}_{2}^{*} \mathrm{Yb}$ (bipy) molecule. One way to rationalize this stabilization is to consider the role of hyperconjugation between the Me and the bipy radical anion, which depends on the electron density in the individual carbon orbitals of the ring. In fact, the substituents on the bipyridine ligand change the reduction potential of the ligand and therefore the energy of the acceptor orbital. ${ }^{38}$ The symmetry of the molecular orbital that contains the unpaired electron and the distribution of unpaired spin density in the $\mathrm{p}_{\pi}$ orbitals of the solvent-separated radical anions of bipy and (4,4'-Me $4_{2}$-bipy) show that the unpaired electron is in a $\pi$-molecular orbital of $\mathrm{b}_{1}$ symmetry (in $\mathrm{C}_{2 v}$ symmetry). The $\mathrm{a}_{H}$ values, which are a measure of the unpaired electron density in a given $\mathrm{p}_{\pi}$ orbital at a given site in the ring, change in subtle ways in bipy and (4,4'-Me 2 -bipy); the EPR spectrum of (4,4'-Me ${ }^{\prime}$-bipy) also shows that unpaired spin density resides on the methyl group. ${ }^{51,52}$ The change in spin density as a function of the site of a methyl or two methyl groups should play a role in determining the energy of the $\pi^{*}$ orbitals and therefore the extent to which they change the energy of the open-shell singlet state relative to the open-shell triplet state. Unfortunately, the EPR spectra of the radical anions of mono-methyl bipyridenes have not been reported.

The properties of the molecules described in this article, especially when taken together with those of the $\mathrm{Cp}_{2}^{*} \mathrm{Yb}$ (bipy) molecule, highlight both the importance of $\mathrm{CI}$ in determining the multiconfigurational singlet ground states and the importance of the net valence change in the first excited state. In fact, the enthalpy changes are sufficiently small that changes in entropy can make the first-excited state at low temperature become the ground state at high temperature, as seen in molecules undergoing spin equilibria. This situation is clearly the case for $\mathrm{Cp}_{2}^{*} \mathrm{Yb}(6-\mathrm{Me}-\mathrm{bipy})$, 
where the change in the Gibbs free energy, $\Delta G=\Delta H-T \Delta S$, changes sign at $T=\Delta H / \Delta S \approx 50 \mathrm{~K}$.

This situation, where the same molecule can take on two isostructural electronic forms, is known as "valence tautomerism." However, the canonical view of tautomerism, such as in bullvalene, ${ }^{53}$ or even valence tautomerism, such as is well known in transition metal complexes containing quinone ligands (for example, see Pierpont et al. ${ }^{16}$ and references therein, as well as a recent report by O'Sullivan et al. ${ }^{54}$ on a conducting polymer variant), does not consider or imply multiconfigurational states, and so we use the term "intermediate-valence tautomerism" to describe this situation. In fact, the presence of IV and strong CIs is due to interacting states that are close in energy, so the presence of IV strongly implies the presence of a tautomeric equilibrium.

It is ironic that the properties of many of the Me-substituted $\mathrm{Cp}_{2}^{*} \mathrm{Yb}(\mathrm{bipy})$ molecules should be so well described as due to IV tautomerism since the properties of $\mathrm{Cp}_{2}^{*} \mathrm{Yb}$ (bipy) were initially hypothesized $^{18,55}$ to be due to valence tautomerism, where the two valence states were considered to be integral, $\mathrm{Yb}(\mathrm{III})$ and $\mathrm{Yb}(\mathrm{II})$. The current view is that the ground state properties of $\mathrm{Cp}_{2}^{*} \mathrm{Yb}(\mathrm{bipy})$ are due to IV behavior arising from an open-shell, multiconfigurational singlet ground state, ${ }^{6,12}$ where the temperature-dependent changes in the magnetic susceptibility are ascribed to a small thermal population of the first excited IV triplet state.

This view of IV tautomerism is very similar to that proposed by LaBute and coworkers ${ }^{17}$ for the case of $\mathrm{Co}(\mathrm{SQ})_{2}$ (phen), where SQ represents a semiquinone complex. In their work, DFT calculations are enhanced to better include many-body interactions using methods generally applied to intermetallic IV compounds such as $\mathrm{CeSn}_{3}$. Using this method, they obtain an integral valent, low-spin state for $\mathrm{Co}(\mathrm{III})$ in the low-temperature form, but an IV high-spin $\mathrm{Co}(+2.28)$ state for the high-temperature form. The apparent need for better treatment of many-body interactions is supported by Co $K$-edge XANES measurements. These results, when taken together with the results reported here, speak strongly for the need to take a closer look at other valence tautomer systems, both by performing higher-order calculations such as CASSCF, and to establish structural signatures of IV behavior.

These results have direct implications outside those of traditional organometallic chemistry 
for understanding the transition between local moment interactions in bulk metals and quantumconfined systems, such as intermetallic nanoparticles and organometallic molecules. In bulk metals, partially localized magnetic orbitals can interact with electrons at the Fermi level, creating an IV, spin-singlet state that is a temperature-independent paramagnet at low temperatures due to Pauli susceptibility. This quasiparticle state, known as a "Kondo singlet," acts like a regular conduction electron, except with a renormalized mass. Although this description captures the essential physics of the interactions and the magnetic and electronic properties, calculating these properties requires a thorough understanding of the many-body interactions involved, and remains a topic of state-of-the-art calculational methods in understanding strongly-correlated electron systems. ${ }^{56-58}$ Describing the properties of materials where such Kondo interactions are important as the system size is decreased and the conduction band is eventually flattened into an atomic-like orbital is a topic of current interest, ${ }^{59-66}$ yet remains poorly understood, in spite of its importance in understanding the properties of nanoscale electronic devices. ${ }^{67-69}$

The present and related ${ }^{17,70}$ work attacks this problem from a different, more molecular-based perspective. As pointed out by Fulde and coworkers, ${ }^{1-3}$ the properties of organometallics, such as cerocene and the molecules described here, can be explained in analogy with the Kondo effects described above, substituting the delocalized electrons in the $\pi$ orbitals of the aromatic ligands for a quantum-confined conduction band. The theoretical basis, apart from the Kondo analogy, does not start from the full many-body theory used for understanding bulk materials, but rather from attempts to understand the electronic and magnetic structure from first principles. The details of the many-body interactions are demonstrated to be critical in understanding these properties, but are included pro re nata, rather than collectively. In this sense, CI-based theories approach the fully interacting many-body theories in a perturbative sense, choosing the most important interactions to include in the active space. This approach can work because of the short-range nature of the interactions in molecular systems with no real conduction band. 


\section{Conclusion}

This article describes experimental and calculational results that strongly bolster previous assertions about intermediate valence (IV) behavior and the importance of configuration interactions (CI) in determining most of the important properties in certain classes of molecules, including bonding, magnetic, and spectroscopic behavior. The intertwining of IV and tautomeric effects, together with their magnetic and structural implications and the small enthalpy and entropy changes involved, indicate that the near-degeneracies that occur in these lanthanide organometallics and their transition-metal cousins create a situation where small perturbations will create large changes in properties. In particular, by using methyl substitutions onto the bipy radical anion in $\mathrm{Cp}_{2}^{*} \mathrm{Yb}(\mathrm{bipy})$, new IV singlet states are made accessible at elevated temperatures. Such states were expected

from basic CI arguments, ${ }^{12}$ but have been realized both in experiment and calculations on the Me-substituted bipy adducts to $\mathrm{Cp}_{2}^{*} \mathrm{Yb}$.

\section{Acknowledgement}

We thank Franziska Bell for several enlightening conversations, and Dr. Fred Hollander and Dr. Antonio DiPasquale for their assistance with the crystallography at CHEXRAY, the U.C. Berkeley X-ray diffraction facility. Portions of this work were supported by the Director, Office of Science, Office of Basic Energy Sciences, of the U.S. Department of Energy (DOE) under Contract No. DE-AC02-05CH11231. and by the U.S. DOE (Los Alamos). LM is a member of the Institut Univeristaire de France. CINES (Montpellier) and CalMip are acknowledged for their generous grant of computing time. X-ray absorption data were collected at the Stanford Synchrotron Radiation Lightsource, a national user facility operated by Stanford University on behalf of the DOE, Office of Basic Energy Sciences. 


\section{Supporting Information Available}

Crystallographic data were deposited with Cambridge Crystallographic Data Centre, CCDC 775405 for $\mathrm{Cp}_{2}^{*} \mathrm{Yb}\left(6,6^{\prime}\right.$-dimethyl-2,2'-bipyridine) (benzene), CCDC 775406 for $\mathrm{Cp}_{2}^{*} \mathrm{Yb}$ (6-methyl-2,2'-bipyridine), CCDC 775407 for $\mathrm{Cp}_{2}^{*} \mathrm{Yb}\left(5,5^{\prime}\right.$-dimethyl-2,2'-bipyridine), and CCDC 775408 for $\mathrm{Cp}_{2}^{*} \mathrm{Yb}\left(6,6^{\prime}\right.$-dimethyl$2,2^{\prime}$-bipyridine). Copies of the data can be obtained free of charge via http://www. ccdc . cam.ac.uk/data_request/cif. Synthesis details, together with crystallographic, NMR, and magnetic susceptibility data, as well as the full reference list of reference 30 and the coordinates from calculated structures, are available as Supporting Information. This material is available free of charge via the Internet at http://pubs.acs.org/.

\section{References}

(1) Neumann, C.-S.; Fulde, P. Z. Phys. B 1989, 74, 277.

(2) Dolg, M.; Fulde, P.; Küchle, W.; Neumann, C.-S.; Stroll, H. J. Chem. Phys. 1991, 94, 3011.

(3) Dolg, M.; Fulde, P.; Stoll, H.; Preuss, H.; Chang, A.; Pitzer, R. M. Chem. Phys. 1995, 195, 71.

(4) Edelstein, N. M.; Allen, P. G.; Bucher, J. J.; Shuh, D. K.; Sofield, C. D.; Kaltsoyannis, N.; Maunder, G. H.; Russo, M. R.; Sella, A. J. Am. Chem. Soc. 1996, 118, 13115.

(5) Amberger, H.; Reddmann, H.; Edelmann, F. J. Organomet. Chem. 2005, 690, 2238.

(6) Booth, C. H.; Walter, M. D.; Daniel, M.; Lukens, W. W.; Andersen, R. A. Phys. Rev. Lett. 2005, 95, 267202.

(7) Coreno, M.; de Simone, M.; Green, J. C.; Kaltsoyannis, N.; Narband, N.; Sella, A. Chem. Phys. Lett. 2006, 432, 17.

(8) Ashley, A.; Balazs, G.; Cowley, A.; Green, J.; Booth, C. H.; O’Hare, D. Chem. Comm. 2007, 1515. 
(9) Balazs, G.; Cloke, G. N.; Green, J. C.; Harker, R. M.; Harrison, A.; Hitchcock, P. B.; Jardine, C. N.; Walton, R. Organometallics 2007, 26, 3111.

(10) Veauthier, J. M.; Schelter, E. J.; Carlson, C. N.; Scott, B. L.; Da Re, R. E.; Thompson, J. D.; Kiplinger, J. L.; Morris, D. E.; John, K. D. Inorg. Chem. 2008, 47, 5841.

(11) Walter, M. D.; Booth, C. H.; Lukens, W. W.; Andersen, R. A. Organometallics 2009, 28, 698.

(12) Booth, C. H.; Walter, M. D.; Kazhdan, D.; Hu, Y.-J.; Lukens, W. W.; Bauer, E. D.; Maron, L.; Eisenstein, O; Andersen, R. A. J. Am. Chem. Soc. 2009, 131, 6480.

(13) Coates, R.; Coreno, M.; DeSimone, M.; Green, J. C.; Kaltsoyannis, N.; Kerridge, A.; Narband, N.; Sella, A. Dalton Trans. 2009, 5943.

(14) Kerridge, A.; Coates, R.; Kaltsoyannis, N. J. Phys. Chem. A 2009, 113, 2896.

(15) Kerridge, A.; Kaltsoyannis, N. J. Phys. Chem. A 2009, 113, 8737.

(16) Pierpont, C. G. Coord. Chem. Rev. 2001, 216-217, 99.

(17) LaBute, M. X.; Kulkarni, R. V.; Endres, R. G.; Cox, D. L. J. Chem. Phys. 2002, 116, 3681.

(18) Schultz, M.; Boncella, J. M.; Berg, D. J.; Tilley, T. D.; Andersen, R. A. Organometallics 2002, 21, 460 .

(19) Walter, M. D.; Berg, D. J.; Andersen, R. A. Organometallics 2006, 25, 3228.

(20) Walter, M. D.; Berg, D. J.; Andersen, R. A. Organometallics 2007, 26, 2296.

(21) Walter, M. D.; Schultz, M.; Andersen, R. A. New. J. Chem. 2006, 30, 238.

(22) Keski-Rahkonen, O.; Krause, M. O. Atomic Data and Nuclear Data Tables 1974, 14, 139.

(23) http://lise.lbl.gov/RSXAP/.

(24) Li, G. G.; Bridges, F.; Booth, C. H. Phys. Rev. B 1995, 52, 6332. 
(25) Ankudinov, A. L.; Rehr, J. J. Phys. Rev. B 1997, 56, R1712.

(26) Stern, E.; Livins, P.; Zhang, Z. Phys. Rev B 1991, 43, 8850.

(27) Booth, C. H.; Hu, Y. J. Phys.: Conf. Ser. 2009, 190, 012028.

(28) Dolg, M.; Stoll, H.; Preuss, H. J. Chem. Phys. 1989, 90, 1730.

(29) Hariharan, P. C.; Pople, J. A. Theor. Chim. Acta 1973, 28, 213.

(30) Frisch, M. J. Gaussian 03, Revision E-01; Gaussian, Inc.: Pittsburgh, PA, 2001.

(31) Becke, A. D. J. Chem. Phys. 1993, 98, 5648.

(32) Burke, K.; Perdew, J. P.; Wang, Y. In Electronic Density Functional Theory: Recent Progress and New Directions, 1998; Dobson, J. F., Vignale, G., Das, M. P., Eds.; Plenum: New York, 1998.

(33) Roos, B.; Andersson, K.; Fulscher, M.; Malmqvist, P.; SerranoAndres, L.; Pierloot, K.; Merchan, M. Multiconfigurational perturbation theory: Applications in electronic spectroscopy. In Advances in Chemical Physics; Wiley: New York, 1996; Vol. 93, p 219.

(34) Tilley, T. D.; Andersen, R. A.; Spencer, B.; Zalkin, A. Inorg. Chem. 1982, 21, 2647.

(35) König, E.; Kreemer, S. Chem. Phys. Lett. 1970, 5, 87.

(36) Fischer, R. D. In NMR of Paramagnetic Molecules; La Mar, G. N., Horrocks, W. D., Holm, R., Eds.; Academic Press: New York, 1973; p 521.

(37) Lawrence, J. M.; Riseborough, P. S.; Booth, C. H.; Sarrao, J. L.; Thompson, J. D.; Osborn, R. Phys. Rev B 2001, 63, 054427.

(38) Ohsawa, Y.; Whangbo, M.; Hanck, K.; Dearmond, M. Inorg. Chem. 1984, 23, 3426.

(39) This lifting of the SS1 and SS2 degeneracy is apparently not large enough to avoid the intruder state problem in the calculations on $\mathrm{Cp}_{2}^{*} \mathrm{Yb}\left(\mathrm{x}, \mathrm{x}^{\prime}-\mathrm{Me}_{2}\right.$-bipy $)$ complexes. 
(40) The MP2 diagnostic based on the CASSCF gives the following parameters: Singlets have $\mathrm{CV}($ Core to Valence excitation $)=-0.009, \mathrm{CU}($ Core to Unoccupied excitation $)=-0.574, \mathrm{UV}$ (Valence to Unoccupied excitation $)=-0.092$, while triplets have $\mathrm{CV}=-0.007, \mathrm{CU}=-0.058$, $\mathrm{UV}=-0.003$. The factor of 100 between the singlet and triplet values of the CU parameter, in particular, strongly favor stabilization of the singlet state.

(41) It is possible that $\mathrm{Yb}$ is divalent in $\mathrm{Cp}_{2}^{*} \mathrm{Yb}\left(6,6^{\prime}-\mathrm{Me}_{2}\right.$-bipy) and the observed $n_{\mathrm{f}}=0.13 \pm 0.03$ is due to some trivalent impurity.

(42) Sorai, M.; Maeda, Y.; Oshio, H. J. Phys. Chem. Solids 1990, 51, 941.

(43) Dai, P.; Zhang, J. D.; Mook, H. A.; S.-H. Liou,; Dowben, P. A.; Plummer, E. W. Phys. Rev. B 1996, 54, 3694.

(44) Billinge, S. J. L.; DiFrancesco, R. G.; Kwei, G. H.; Neumeier, J. J.; Thompson, J. D. Phys. Rev. Lett. 1996, 77, 715.

(45) Booth, C. H.; Bridges, F.; Kwei, G. H.; Lawrence, J. M.; Cornelius, A. L.; Neumeier, J. J. Phys. Rev. Lett. 1998, 80, 853.

(46) Crozier, E. D.; Rehr, J. J.; Ingalls, R. Amorphous descriptions (including Debye and Einstein). In X-Ray Absorption: Principles, Applications, Techniques of EXAFS, SEXAFS, XANES; Konigsberger, D., Prins, R., Eds.; Wiley: New York, 1988; p 373.

(47) Booth, C. H.; Sarrao, J. L.; Hundley, M. F.; Cornelius, A. L.; Kwei, G. H.; Bianchi, A.; Fisk, Z.; Lawrence, J. M. Phys. Rev. B 2001, 63, 224302.

(48) Booth, C. H.; Bauer, E. D.; Bozin, E.; Billinge, S. J. L.,; Walter, M. D. J. Phys.: Conf. Ser. in press.

(49) Allen, J. W.; Martin, R. M. Phys. Rev. Lett. 1982, 49, 1106.

(50) Felner, I.; Nowik, I. Phys. Rev. B 1986, 33, 617. 
(51) Kaim, W. J. Am. Chem. Soc. 1982, 104, 3833.

(52) Kaim, W. J. Am. Chem. Soc. 1982, 104, 7385, correction.

(53) Doering, W. v. E.; Roth, W. R. Tetrahedron 1963, 19, 715.

(54) O’Sullivan, T. J.; Djukic, B.; Dube, P. A.; Lemaire, M. T. Chem. Comm. 2009, 1903.

(55) Veauthier, J. M.; Schelter, E. J.; Kuehl, C. J.; Clark, A. E.; Scott, B. L.; Morris, D. E.; Martin, R. L.; Thompson, J. D.; Kiplinger, J. L.; John, K. D. Inorg. Chem. 2005, 44, 5911.

(56) Fulde, P.; Keller, J.; Zwicknagl, G. Solid State Physics 1988, 41, 1.

(57) Hewson, A. C. The Kondo Problem to Heavy Fermions; Cambridge University Press: Cambridge, 1993.

(58) Flint, R.; Dzero, M.; Coleman, P. Nat. Phys. 2008, 4, 643.

(59) Thimm, W. B.; Kroha, J.; von Delft, J. Phys. Rev. Lett. 1999, 82, 2143.

(60) Schlottmann, P. Phys. Rev. B 2002, 65, 024420.

(61) Schlottmann, P. Phys. Rev. B 2002, 65, 024431.

(62) Schlottmann, P. Phys. Rev. B 2002, 65, 174407.

(63) Cornaglia, P. S.; Balseiro, C. A. Phys. Rev. B 2002, 66, 115303.

(64) Verdozzi, C.; Luo, Y.; Kioussis, N. Phys. Rev. B 2004, 70, 132404.

(65) Mishra, S. N.; Bose, S.; Vasa, P.; Ayyub, P. Phys. Rev. B 2005, 71, 094429.

(66) Hand, T.; Kroha, J.; Monien, H. Phys. Rev. Lett. 2006, 97, 136604.

(67) Goldhaber-Gordon, D.; Shtrikman, H.; Mahalu, D.; Abusch-Magder, D.; Meirav, U.; Kastner, M. A. Nature (London) 1998, 391, 156. 
(68) Liang, W.; Shores, M. P.; Bockrath, M.; Long, J. R.; Park, H. Nature (London) 2002, 417, 725.

(69) Zhao, A.; Li, Q.; Chen, L.; Xiang, H.; Wang, W.; Pan, S.; Wang, B.; Xiao, X.; Yang, J.; Hou, J.; Zhu, Q. Science 2005, 309, 1542.

(70) Huang, P.; Carter, E. A. Nano Lett. 2006, 6, 1146. 


\section{DISCLAIMER}

This document was prepared as an account of work sponsored by the United States Government. While this document is believed to contain correct information, neither the United States Government nor any agency thereof, nor The Regents of the University of California, nor any of their employees, makes any warranty, express or implied, or assumes any legal responsibility for the accuracy, completeness, or usefulness of any information, apparatus, product, or process disclosed, or represents that its use would not infringe privately owned rights. Reference herein to any specific commercial product, process, or service by its trade name, trademark, manufacturer, or otherwise, does not necessarily constitute or imply its endorsement, recommendation, or favoring by the United States Government or any agency thereof, or The Regents of the University of California. The views and opinions of authors expressed herein do not necessarily state or reflect those of the United States Government or any agency thereof or The Regents of the University of California. 


\section{Graphical TOC Entry}

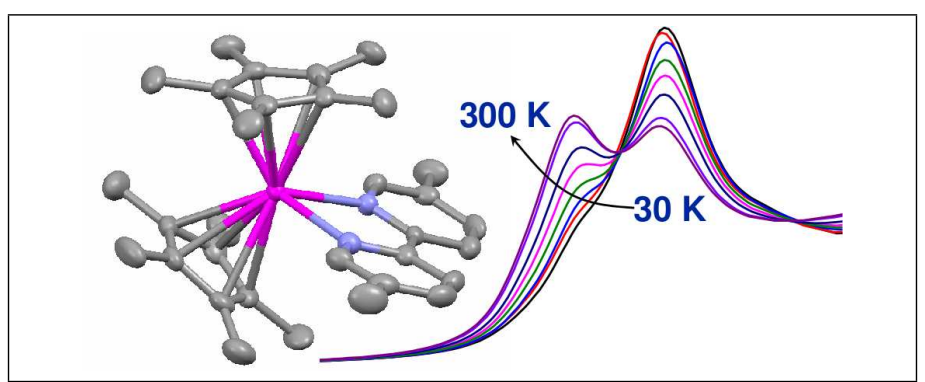

